\title{
The Dehydropolymerization of $\mathrm{H}_{3} \mathrm{~B} \cdot \mathrm{NMeH}_{2}$ to form Polyaminobo- ranes using [Rh(Xantphos-alkyl)] Catalysts.
}

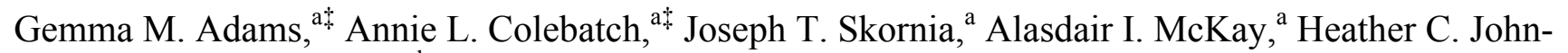 \\ son, ${ }^{a}$ Guy C. Lloyd-Jones, ${ }^{b}$ Stuart A. Macgregor, ${ }^{c}$ Nicholas A. Beattie, ${ }^{c}$ Andrew S. Weller*a \\ ${ }^{a}$ Chemistry Research Laboratories, Mansfield Road, Oxford, OX1 3TA, UK ${ }^{\mathrm{b}}$ School of Chemistry, University \\ of Edinburgh, Edinburgh, EH9 3FJ, UK ${ }^{\mathrm{c}}$ Institute of Chemical Sciences, Heriot Watt University, Edinburgh, EH14 4AS, UK
}

\begin{abstract}
A systematic study of the catalyst structure and overall charge for the dehydropolymerization of $\mathrm{H}_{3} \mathrm{~B} \cdot \mathrm{NMeH}_{2}$ to form $N$ methyl polyaminoborane is reported using catalysts based upon neutral and cationic $\{\mathrm{Rh}(\mathrm{Xantphos}-\mathrm{R}\}\}$ fragments, in which $\mathrm{PR} \mathrm{R}_{2}$ groups are selected from Et, ${ }^{\mathrm{i}} \mathrm{Pr}$ and ${ }^{\mathrm{t}} \mathrm{Bu}$. The most efficient systems are based upon $\left\{\mathrm{Rh}\left(\mathrm{Xantphos}-{ }^{\mathrm{i}} \mathrm{Pr}\right\}\right\}$, i.e. $\left[\mathrm{Rh}\left(\kappa^{3}-\mathrm{P}, \mathrm{O}, \mathrm{P}-\right.\right.$ Xantphos $\left.-\mathrm{i} P r)(\mathrm{H})_{2}\left(\eta^{1}-\mathrm{H}_{3} \mathrm{~B} \cdot \mathrm{NMe}_{3}\right)\right]\left[\mathrm{BAr}{ }_{4}^{\mathrm{F}}\right], \mathbf{6}$, and $\mathrm{Rh}\left(\kappa^{3}-\mathrm{P}, \mathrm{O}, \mathrm{P}-\mathrm{X}\right.$ antphos $\left.-{ }^{\mathrm{i}} \mathrm{Pr}\right) \mathrm{H}, \mathbf{1 1}$. While $\mathrm{H}_{2}$ evolution kinetics show both are fast catalysts $\left(\mathrm{ToF} \sim 1500 \mathrm{hr}^{-1}\right)$, and polymer growth kinetics for dehydropolymerization suggest a classical chain growth process for both, neutral $11\left(M_{\mathrm{n}}=28,000 \mathrm{~g} \mathrm{~mol}^{-1}, D=1.9\right)$ promotes significantly higher degrees of polymerization than cationic $\mathbf{6}\left(M_{\mathrm{n}}=\right.$ $\left.9,000 \mathrm{~g} \mathrm{~mol}^{-1}, \oslash=2.9\right)$. For 6 isotopic labelling studies suggest a rate determining $\mathrm{NH}$ activation, while speciation studies, coupled with DFT calculations, show the formation of a dimetalloborylene $\left[\left\{\mathrm{Rh}\left(\kappa^{3}-\mathrm{P}, \mathrm{O}, \mathrm{P}-\mathrm{X} \text { antphos- }-{ }^{\mathrm{i}} \mathrm{Pr}\right){ }_{2} \mathrm{~B}\right]^{+}\right.$as the, likely dormant, end product of catalysis. A dual mechanism is proposed for dehydropolymerization, in which neutral hydrides (formed by hydride transfer in cationic 6 to form a boronium co-product) are the active catalysts for dehydrogenation to form aminoborane. Contemporaneous chain-growth polymer propagation occurs on a separate metal center via head-to-tail end chain B-N bond formation of the aminoborane monomer, templated by an aminoborohydride-containing catalyst.
\end{abstract}

1. Introduction. The catalyzed dehydropolymerization of ammonia-borane or primary amine-boranes, such as $\mathrm{H}_{3} \mathrm{~B} \cdot \mathrm{NMeH}_{2}$, provides a potentially useful methodology for the production of new inorganic polymeric materials, polyaminoboranes (e.g. $N$-methyl polyaminoborane $\left.\left(\mathrm{H}_{2} \mathrm{BNMeH}\right)_{\mathrm{n}}\right)$, which have alternating BN main-chain units, Scheme $1 \mathrm{~A}$. Although these are isoelectronic with technologically pervasive polyolefins such as polypropylene their synthesis and properties are virtually unexplored, ${ }^{1}$ apart from a few examples that demonstrate their use as precursors for $\mathrm{BN}$-based materials. $^{2}$ A variety of catalysts ${ }^{1 \mathrm{c}, 3}$ have been shown to promote the dehydropolymerization of $\mathrm{H}_{3} \mathrm{~B} \cdot \mathrm{NH}_{3}{ }^{4}$ and in particular $\mathrm{H}_{3} \mathrm{~B} \cdot \mathrm{NMeH}_{2},{ }^{2 \mathrm{~d}, 4 \mathrm{a}, \mathrm{b}, 5}$ for example $\operatorname{Ir}(\mathrm{POCOP})(\mathrm{H})_{2}, \quad \mathbf{A}$ (POCOP $\left.=\kappa^{3}-\mathrm{C}_{6} \mathrm{H}_{3}-2,6-\left(\mathrm{OP}^{\mathrm{t}} \mathrm{Bu}_{2}\right)_{2}\right),{ }^{4 \mathrm{a}}$ $(\mathrm{PNHP}) \mathrm{Fe}(\mathrm{H})(\mathrm{CO})\left(\mathrm{HBH}_{3}\right)\left(\mathrm{PNHP}=\mathrm{HN}\left(\mathrm{CH}_{2} \mathrm{CH}_{2} \mathrm{P}^{\mathrm{i}} \mathrm{Pr}_{2}\right)_{2}\right), \mathbf{B},{ }^{6}$ and $\left[\mathrm{Rh}\left\{\mathrm{Ph}_{2} \mathrm{P}\left(\mathrm{CH}_{2}\right)_{3} \mathrm{PPh}_{2}\right\}\left(\eta^{6}-\mathrm{FC}_{6} \mathrm{H}_{5}\right)\right]\left[\mathrm{BAr}_{4}^{\mathrm{F}}\right] \quad\left(\mathrm{Ar}^{\mathrm{F}}=3,5-\right.$ $\left.\left(\mathrm{CF}_{3}\right)_{2} \mathrm{C}_{6} \mathrm{H}_{3}\right) \quad \mathrm{C}$, ${ }^{5 \mathrm{a}}$ Scheme 1B. These catalysts have been shown to operate under homogeneous conditions, although heterogeneous examples have also been reported, ${ }^{7}$ and the switch between these two mechanistic extremes can be controlled by pre-catalyst structure. ${ }^{8}$ However, catalyst development that originates through an understanding of the mechanism(s) that operate in dehydropolymerization is still in its infancy. ${ }^{1 \mathrm{c}-\mathrm{e}, 4 \mathrm{a}, \mathrm{c}, \mathrm{e}, 5 \mathrm{~d}, 6,9}$ Although many of the individual fundamental steps have been studied in some detail, ${ }^{10}$ e.g. dehydrogenation to form aminoboranes $\mathrm{s}^{5 \mathrm{~d}, 11}$ and the formation of oligomeric di- and tri-borazanes ${ }^{1 \mathrm{a}, \mathrm{c}, 12}$ by dehydrocoupling processes, the roles of metal/ligand fragment in both promoting dehydrogenation of the precursor amine-borane and coupling (i.e. chain propagation) to form polymeric material have not been fully delineated. Valence isoelectronic primary phos- phine-boranes also undergo dehydropolymerization; ${ }^{13}$ for which mechanistic studies give complementary insight.

Scheme 1. (A) Dehydropolymerization of $\mathrm{H}_{3} \mathrm{~B} \cdot \mathrm{NMeH}_{2}$. (B) Examples of catalysts $\left(M_{\mathrm{n}}=\mathrm{g} \mathrm{mol}^{-1}\right)$. $\left[\mathrm{BAr}^{\mathrm{F}}{ }_{4}\right]^{-}$anions are not shown.

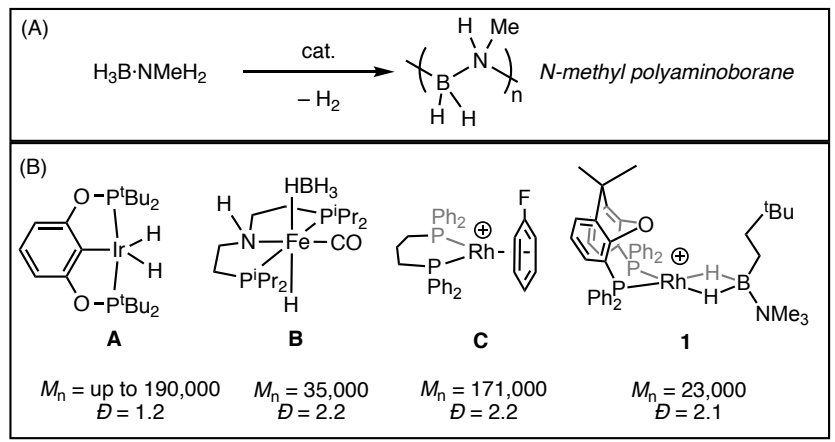

In contrast with olefin polymerization ${ }^{14}$ where the monomer (e.g. propene) is stable, aminoboranes such as $\mathrm{H}_{2} \mathrm{~B}=\mathrm{NH}_{2}$ or $\mathrm{H}_{2} \mathrm{~B}=\mathrm{NMeH}$ are unstable towards oligomerization and can only be observed as transient species at low temperatures, or trapped on metal centers. ${ }^{5 \mathrm{~d}, 11 \mathrm{~b}, 15}$ This presents an additional challenge for studying amine-borane dehydropolymerization as the catalyst needs to operate in a bifunctional ${ }^{1 \mathrm{e}, 4 \mathrm{e}}$ manner, dehydrogenating amine-boranes (via $\mathrm{B}-\mathrm{H}$ and $\mathrm{N}-\mathrm{H}$ activation) and then subsequently controlling the B-N bondforming polymerization events (Scheme 2). Further complicating the mechanistic analysis and control of polymer chain propagation is that aminoboranes have been shown to undergo a number of different reactions when generated in situ in the 
absence of a catalyst. For example: dehydrocoupling to form borazines, ${ }^{1 \mathrm{e}}$ autocatalytic roles in dehydrocoupling processes, ${ }^{16}$ hydrogen-redistribution reactions, ${ }^{17}$ polymerization to form product that is insoluble, e.g. $\left(\mathrm{H}_{2} \mathrm{BNH}_{2}\right)_{\mathrm{n}}$, ${ }^{4 \mathrm{a}}$ or low molecular weight, e.g. $\left(\mathrm{H}_{2} \mathrm{BNMeH}\right)_{\mathrm{n}}{ }^{15}$ In addition, dehydrogenation processes (on- or off-metal) have been proposed to be promoted by secondary interactions such as $\mathrm{N}-\mathrm{H}(\delta+) \cdots(\delta-$ )H-B dihydrogen bonds. ${ }^{16 a, 18}$ As the numerous studies on the dehydrocoupling of the secondary amine-borane, $\mathrm{H}_{3} \mathrm{~B} \cdot \mathrm{NMe}_{2} \mathrm{H}$, have shown, differences in the likely mechanistic pathways can also occur by changing the catalyst. ${ }^{1 \mathrm{c}}$

Scheme 2. On- and off-metal (dehydro)polymerization of amine- and aminoboranes.

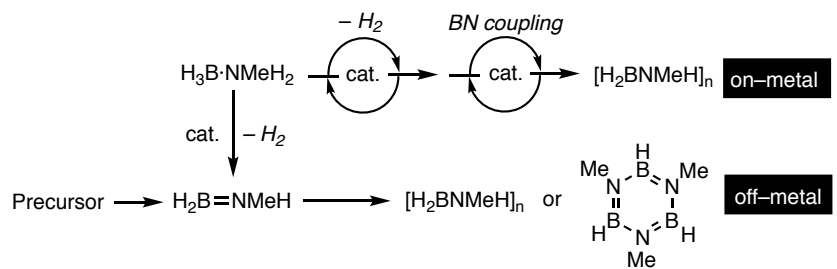

We have recently reported that cationic precatalysts based upon $\left[\mathrm{Rh}\left(\kappa^{2}-\mathrm{P}, \mathrm{P}-\mathrm{X}\right.\right.$ antphos- $\left.\mathrm{Ph}\right)\left(\eta^{2}-\right.$ $\left.\left.\mathrm{H}_{2} \mathrm{~B}\left(\mathrm{CH}_{2} \mathrm{CH}_{2}{ }^{\mathrm{t}} \mathrm{Bu}\right) \mathrm{NMe}_{3}\right)\right]\left[\mathrm{BAr}^{\mathrm{F}}{ }_{4}\right]$, 1, (Xantphos-Ph $=4,5-$ bis(diphenylphosphino)-9,9-dimethylxanthene) are particularly effective for the dehydropolymerization of $\mathrm{H}_{3} \mathrm{~B} \cdot \mathrm{NMeH}_{2}$, operating at $0.2 \mathrm{~mol} \%$ in $\mathrm{FC}_{6} \mathrm{H}_{5}$ solvent to produce polyaminoborane of $M_{\mathrm{n}}=23,000 \mathrm{~g} \mathrm{~mol}^{-1}, \emptyset=2.1$ (Scheme 1). ${ }^{5 \mathrm{~b}} \mathrm{~A}$ controlled $^{19}$ dehydrogenation/coordination/insertion ${ }^{1 \mathrm{e}, 4 \mathrm{c}}$ mechanism for chain propagation was proposed on the basis of: (i) saturation kinetics being observed (and modelled) in analogous $\mathrm{H}_{3} \mathrm{~B} \cdot \mathrm{NMe}_{2} \mathrm{H}$ dehydrocoupling, (ii) an inverse relationship between catalyst loading and polymer molecular weight, and (iii) $\mathrm{H}_{2}$ acting as a chain termination agent to produce significantly lower molecular weight polymer $\left(M_{\mathrm{n}}=2,800 \mathrm{~g}\right.$ $\left.\mathrm{mol}^{-1}, Ð=1.8\right)$. In such a mechanism the metal is proposed to promote dehydrogenative insertion of $\mathrm{H}_{3} \mathrm{~B} \cdot \mathrm{NMeH}_{2}$, via a transient ${ }^{15,20}$ metal-bound $\mathrm{H}_{2} \mathrm{~B}=\mathrm{NMeH}$ fragment (Scheme $3 \mathrm{~A}$ ). Although the identity of the true catalyst remains unresolved, in part due to the low catalyst loadings used $(0.2 \mathrm{~mol} \%)$ and an induction period being observed before catalysis, a $\mathrm{Rh}(\mathrm{III})$ dihydride was implicated as the first-formed species (Scheme $3 \mathrm{~B})$. This was proposed to evolve to a $\mathrm{Rh}(\mathrm{III})$-amidoborane, responsible for chain propagation. Stoichiometric experiments also demonstrated hemilability ${ }^{21}$ of the Xantphos-Ph ligand between $c i s-\kappa^{2}-\mathrm{P}, \mathrm{P}$ and $m e r-\kappa^{3}-\mathrm{P}, \mathrm{O}, \mathrm{P}$. The actual catalyst

Scheme 3. (A) Proposed coordination/dehydrogenation/insertion mechanism. (B) Cationic Xantphos-Ph precatalyst. $\left[\mathrm{BAr}^{\mathrm{F}}{ }_{4}\right]^{-}$anions are not shown.

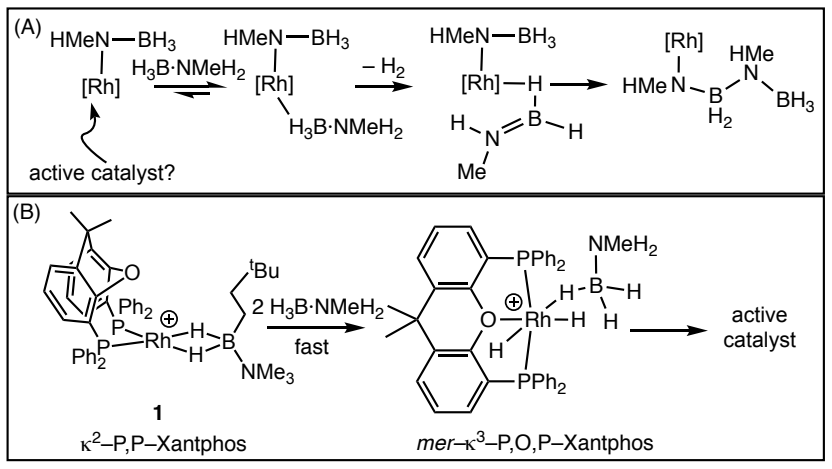

formed in situ could also be cationic or neutral (formed via hydride transfer from borane ${ }^{5 \mathrm{~d}, 22}$ ), or have a bimetallic motif as commented upon in other systems based upon kinetic studies or products characterized by single-crystal X-ray diffraction. ${ }^{5 \mathrm{c}, \mathrm{d}, 23}$ This mechanism differs from those proposed to operate for $\mathrm{Fe}\left(\mathrm{PhNCH}_{2} \mathrm{CH}_{2} \mathrm{NPh}\right)\left(\mathrm{Cy}_{2} \mathrm{PCH}_{2} \mathrm{CH}_{2} \mathrm{PCy}_{2}\right)$, $\mathrm{H}_{3} \mathrm{~B} \cdot \mathrm{NH}_{3}{ }^{4 \mathrm{c}}, \quad \mathbf{A},{ }^{4 \mathrm{a}, 24}$ and bifunctional $\mathrm{M}(\mathrm{PNP}) \mathrm{H}\left(\mathrm{PMe}_{3}\right)$ / $\mathrm{H}_{3} \mathrm{~B} \cdot \mathrm{NH}_{3}(\mathrm{M}=\mathrm{Fe}, \mathrm{Ru})^{4 \mathrm{e}, \mathrm{f}}$ systems, for which metal-based dehydrogenation occurs but the aminoborane undergoes metal-based polymerization at a different metal center.

While the parent Xantphos-Ph ligand is well-established in organometallic catalysis, ${ }^{25}$ the alkyl-substituted versions have only recently been explored, ${ }^{26}$ in particular by Esteruelas. ${ }^{4 \mathrm{~d}, 27}$ Scheme 4 shows examples of Rh-based complexes, both cationic and neutral. Relevant to this paper, neutral Rh-hydride $\mathbf{F}$ has been shown to be an effective catalyst for the dehydrogenation of $\mathrm{H}_{3} \mathrm{~B} \cdot \mathrm{NH}_{3}$ and $\mathrm{H}_{3} \mathrm{~B} \cdot \mathrm{NMe}_{2} \mathrm{H} ;{ }^{28}$ while it also undergoes rapid $\mathrm{C}-\mathrm{H}$ activation with fluoroarenes $(\mathbf{G}),{ }^{27 \mathrm{a}}$ and $\mathrm{B}-\mathrm{H}$ activation with boranes. ${ }^{27 a}$ Interestingly for $\mathrm{Rh}-$ based systems, the complexes that can be observed exclusively offer the mer$\kappa^{3}-\mathrm{P}, \mathrm{O}, \mathrm{P}$ binding mode in the ground state, i.e. as a pincer ligand; while $f a c-\kappa^{3}-\mathrm{P}, \mathrm{O}, \mathrm{P}$ or $c i s-\kappa^{2}-\mathrm{P}, \mathrm{P}$ coordination modes have been observed in osmium systems. ${ }^{27 \mathrm{~d}} \mathrm{~A} c i s-\kappa^{2}-\mathrm{P}, \mathrm{P}$ coordination geometry is shown by the less bulky ethyl analogue coordinated with $\mathrm{Pd}, \mathbf{H}^{260}$

Scheme 4. Examples of alkyl substituted Xantphos-based ligands. Anions are not shown. $R={ }^{\mathrm{i}} \mathrm{Pr},{ }^{\mathrm{t}} \mathrm{Bu}$.

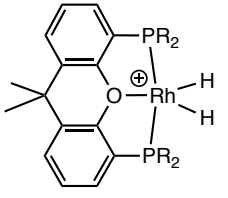

D

Goldman

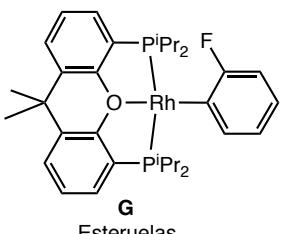

Esteruelas

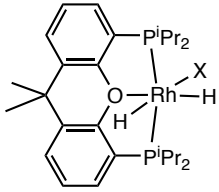

$E(X=O T f, C l)$ Goldman \& Esteruelas

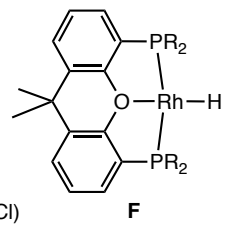

Goldman \& Esteruelas

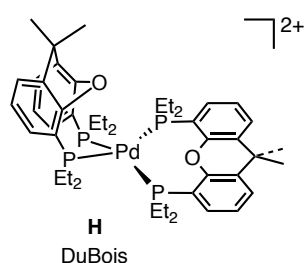

These reports demonstrate a rich-landscape of coordination motifs and bond-activations that alkyl Xantphos ligands promote when coordinated to rhodium. When coupled with our recent report using precatalyst $1,{ }^{5 b}$ this encourages their exploration in the dehydropolymerization of $\mathrm{H}_{3} \mathrm{~B} \cdot \mathrm{NMeH}_{2}$. We report here a systematic study of dehydropolymerization using both cationic (e.g. based upon D) and neutral (e.g. F) $\mathrm{Rh}-$ precursors of the alkyl-substituted Xantphos motif, in which the ligating $\mathrm{PR}_{2}$ groups are also systematically varied between Xantphos-Et, Xantphos- ${ }^{\mathrm{i}} \mathrm{Pr}$ and Xantphos- ${ }^{\mathrm{t}} \mathrm{Bu}$.

\section{2}

2.1 Synthesis and reactivity of cationic precursor complexes $\left[\mathbf{R h}\left(\kappa^{3}-\mathbf{P}, \mathbf{O}, \mathbf{P}-X\right.\right.$ antphos- $\left.\mathbf{R}\right)(\mathbf{H})_{2}\left(\eta^{1}-\right.$ $\left.\left.\mathrm{H}_{3} \mathrm{~B} \cdot \mathrm{NMe}_{3}\right)\right]\left[\mathrm{BAr}^{\mathrm{F}}{ }_{4}\right], \mathbf{R}=\mathrm{Et},{ }^{\mathrm{i}} \mathrm{Pr}$, and $\left[\mathrm{Rh}\left(\mathrm{\kappa}^{3}-\mathrm{P}, \mathrm{O}, \mathrm{P}-\right.\right.$ Xantphos-R)(H) $\left.)_{2}\right]\left[\mathbf{B A r}{ }_{4}^{\mathbf{F}}\right], \mathbf{R}={ }^{\mathbf{t}} \mathbf{B u}$. Catalyst precursors are ideally operationally unsaturated, to allow formation of a $\mathrm{H}_{3} \mathrm{~B} \cdot \mathrm{NMeH}_{2}$ sigma-complex, ${ }^{29}$ and also available as pure crystalline material. For the Xantphos-Ph system both Rh(I), 1, and $\mathrm{Rh}(\mathrm{III})$ dihydride, $\left[\mathrm{Rh}\left(\kappa^{3}-\mathrm{P}, \mathrm{O}, \mathrm{P}-\mathrm{Xantphos}-\right.\right.$ $\left.\mathrm{Ph})(\mathrm{H})_{2}\left(\eta^{1}-\mathrm{H}_{3} \mathrm{~B} \cdot \mathrm{NMe}_{3}\right)\right]\left[\mathrm{BAr}_{4}^{\mathrm{F}}\right], 2$, precursors have a weakly 
bound amine-borane acting as a place-holder ligand. ${ }^{5 b}$ These are conveniently prepared from a $\left[\mathrm{Rh}\left(\kappa^{2}-\mathrm{P}, \mathrm{P}-\mathrm{X}\right.\right.$ antphos$\mathrm{Ph})(\mathrm{NBD})]\left[\mathrm{BAr}^{\mathrm{F}}{ }_{4}\right]$ precursor $(\mathrm{NBD}=$ norbornadiene $),{ }^{30}$ and we have used the same route for alkyl-substituted Xantphos complexes.
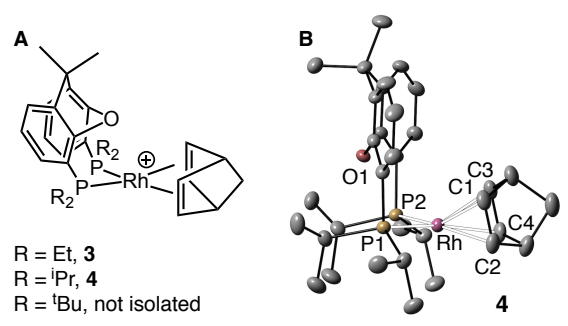

Figure 1. (A) Complexes 3 and 4. (B) Molecular structure of the cationic portion of $\mathbf{4}$, displacement ellipsoids at the $30 \%$ probability level, $\mathrm{H}$-atoms and $\left[\mathrm{BAr}_{4}\right]^{-}$anion are not shown. Selected bond distances $(\AA)$ and angles $\left({ }^{\circ}\right)$ : Rh-P1, 2.3897(8); Rh1-P2, 2.3659(8); Rh1-O1, 3.161(2); P1-Rh1-P2, 101.72(3).

Addition of Xantphos-Et to $\left[\mathrm{Rh}(\mathrm{NBD})_{2}\right]\left[\mathrm{BAr}_{4}^{\mathrm{F}}\right]$ in $\mathrm{CH}_{2} \mathrm{Cl}_{2}$ solution gives $\left[\mathrm{Rh}\left(\kappa^{2}-\mathrm{P}, \mathrm{P}-\mathrm{Xantphos}-\mathrm{Et}\right)(\mathrm{NBD})\right]\left[\mathrm{BAr}^{\mathrm{F}}{ }_{4}\right], \mathbf{3}$, after recrystallization from $\mathrm{CH}_{2} \mathrm{Cl}_{2}$ /pentane, as an orange microcrystalline powder. In a similar manner, $\left[\mathrm{Rh}\left(\kappa^{2}-\mathrm{P}, \mathrm{P}-\right.\right.$ Xantphos $\left.\left.-{ }^{\mathrm{i}} \mathrm{Pr}\right)(\mathrm{NBD})\right]\left[\mathrm{BAr}{ }_{4}^{\mathrm{F}}\right], \mathbf{4}$, can be prepared. Complexes 3 and $\mathbf{4}$ were characterized by variable temperature NMR spectroscopy (including an Eyring analysis), elemental analysis, ESI-MS (Electrospray Ionization-Mass Spectrometry), and also by single crystal $\mathrm{X}$-ray diffraction (Fig. 1B shows 4 , Fig. S23 for 3), which show a $c i s-\kappa^{2}-\mathrm{P}, \mathrm{P}$ coordination geometry for the alkyl Xantphos ligands. The corresponding NBD adduct using the Xantphos- ${ }^{t} \mathrm{Bu}$ ligand could not be prepared, as commented upon by Goldman and co-workers, ${ }^{26 \mathrm{~b}}$ the bulky ${ }^{\mathrm{t}} \mathrm{Bu}$ groups disfavouring the $c i s-\kappa^{2}-\mathrm{P}, \mathrm{P}$ coordination geometry (Supporting Materials).

Addition of $\mathrm{H}_{2}$ to a $1,2-\mathrm{F}_{2} \mathrm{C}_{6} \mathrm{H}_{4}$ solution of complex 3 or 4 containing 1 equivalent of $\mathrm{H}_{3} \mathrm{~B} \cdot \mathrm{NMe}_{3}$ results in the formation of $\left[\mathrm{Rh}\left(\kappa^{3}-\mathrm{P}, \mathrm{O}, \mathrm{P}-\mathrm{Xantphos}-\mathrm{R}\right)(\mathrm{H})_{2}\left(\eta^{1}-\mathrm{H}_{3} \mathrm{~B} \cdot \mathrm{NMe}_{3}\right)\right]\left[\mathrm{BAr}_{4}^{\mathrm{F}}{ }_{4}\right]$ $\left(\mathbf{5}, \mathrm{R}=\mathrm{Et} ; \mathbf{6}, \mathrm{R}={ }^{\mathrm{i}} \mathrm{Pr}\right)$, that can be isolated as off-white solids,

A

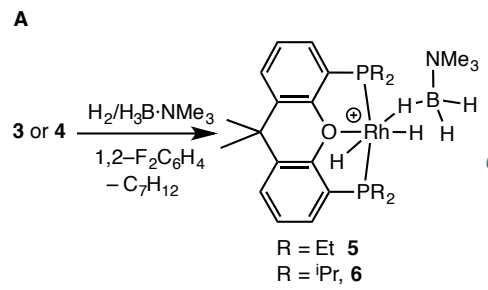

c

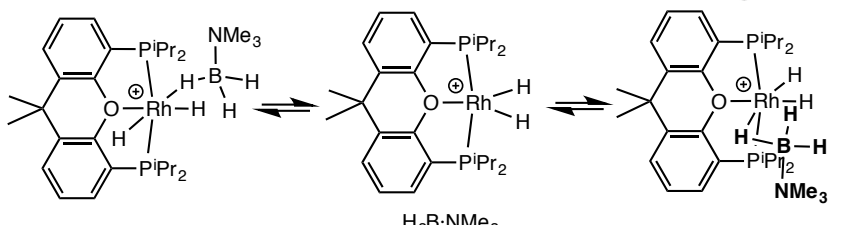

Figure 2. (A) Complexes 5 and 6. (B) Molecular structure of the cationic portion of $\mathbf{6}$, displacement ellipsoids at the $30 \%$ probability level, $\mathrm{H}$-atoms and $\left[\mathrm{BAr}_{4}^{\mathrm{F}}\right]^{-}$anion are not shown. Selected bond distances $(\AA)$ and angles $\left({ }^{\circ}\right)$ : Rh-P1, 2.2650(13); Rh1-P2, 2.2490(15); Rh1-B1, 2.783(6); Rh1-O1, 2.192(3), B1-N1, 1.607(7); P1-Rh1-P2, 160.45(5). (C) Proposed fluxional process for 6 .
Figure 2A. Complex 6 was characterized by a single-crystal $\mathrm{X}$-ray diffraction study (Fig. 2B), which shows a $m e r-\kappa^{3}-$ Xantphos- ${ }^{\mathrm{i}} \mathrm{Pr} \mathrm{Rh}(\mathrm{III})$ cis-dihydride motif with a supporting sigma-bound ${ }^{29} \eta^{1}-\mathrm{H}_{3} \mathrm{~B} \cdot \mathrm{NMe}_{3}$ ligand. The overall geometry is very similar to that measured for $2{ }^{31}$ in particular the $\mathrm{Rh} \cdots \mathrm{B}$ distance $[6,2.783(6) \AA ; 2,2.759(6) \AA]$ and is also similar to $\left[\mathrm{Ru}(\right.$ Xantphos- $\left.\mathrm{Ph})\left(\mathrm{PPh}_{3}\right)\left(\eta^{1}-\mathrm{H}_{3} \mathrm{~B} \cdot \mathrm{NMeH}_{2}\right)(\mathrm{H})\right]\left[\mathrm{BAr}_{4}^{\mathrm{F}}{ }_{4}{ }^{32}\right.$

The solution NMR data show that $6\left(\mathrm{R}={ }^{\mathrm{i}} \mathrm{Pr}\right)$ is fluxional at $298 \mathrm{~K}$, while at this temperature $5(\mathrm{R}=\mathrm{Et})$ is not. For $\mathbf{6}$ a single hydride environment is observed at $\delta-19.09$, of relative integral $2 \mathrm{H}$, as well as a quadrupolar broadened, $3 \mathrm{H}$ relative integral, signal at $\delta 0.08$ assigned to the $\mathrm{Rh} \cdots \mathrm{H}-\mathrm{B}$ that is undergoing rapid site exchange between bridging and terminal $\mathrm{B}-\mathrm{H} .{ }^{29,33}$ In the ${ }^{11} \mathrm{~B}$ NMR spectrum a signal is observed at $\delta-$ 9.9, consistent with an $\eta^{1}$-bound borane. ${ }^{34}$ A single Xantphos${ }^{\mathrm{i}} \mathrm{Pr} \mathrm{CMe}_{2}$ environment is observed. The ${ }^{31} \mathrm{P}\left\{{ }^{1} \mathrm{H}\right\}$ NMR spectrum shows one environment, $\delta 66.5[J(\mathrm{RhP})=111 \mathrm{~Hz}]$. Progressive cooling to $200 \mathrm{~K}$ reveals a low temperature limiting spectrum consistent with the solid-state structure that now shows two hydride environments at $\delta-17.62$ and $\delta-19.97$ (modelled as a dtd), an upfield shifted $\mathrm{Rh} \cdots \mathrm{H}-\mathrm{B}$ signal (relative integral $3 \mathrm{H}$ ) at $\delta-0.58$, and two Xantphos ${ }^{\mathrm{i}} \mathrm{Pr} \mathrm{CMe}_{2}$ environments. An Eyring analysis of the hydride signals in complex 6 gives activation parameters $\Delta \mathrm{H}^{\star}=59(4) \mathrm{kJ} \mathrm{mol}^{-1}$ and $\Delta \mathrm{S}^{*}=+37(15) \mathrm{J} \mathrm{K}^{-1} \mathrm{~mol}^{-1}$ for this fluxional process. These data are consistent with a mechanism in which the $\mathrm{H}_{3} \mathrm{~B} \cdot \mathrm{NMe}_{3}$ ligand dissociates and re-coordinates on the other side, via a $\left(\right.$ known $\left.^{26 \mathrm{~b}}\right)$ symmetric 16 -electron intermediate $\left[\mathrm{Rh}\left(\mathrm{\kappa}^{3}-\right.\right.$ $\left.\left.\mathrm{P}, \mathrm{O}, \mathrm{P}-\mathrm{Xantphos}-{ }^{\mathrm{i}} \mathrm{Pr}\right)(\mathrm{H})_{2}\right]^{+}$, Figure $2 \mathrm{C}$. These activation parameters are similar to those reported for related fluxional process in $\left[\mathrm{Rh}\left(\kappa^{3}-\mathrm{P}, \mathrm{O}, \mathrm{P}-\mathrm{Xantphos}-\mathrm{i} \mathrm{Pr}\right)(\mathrm{H})_{2}\right][\mathrm{OTf}]\left[\Delta \mathrm{H}^{*}=\right.$ 64(3) $\mathrm{kJ} \mathrm{mol}^{-1}$ and $\left.\Delta \mathrm{S}^{*}=+66(8) \mathrm{J} \mathrm{K}^{-1} \mathrm{~mol}^{-1}\right]$. ${ }^{4 \mathrm{~d}}$ Complex 5 displays NMR data that are very similar to those measured at low temperature for $\mathbf{6}$. We suggest these differences are driven by the steric effects of Et versus ${ }^{\mathrm{i}} \mathrm{Pr}$. This influence of sterics is further demonstrated in that addition of $\mathrm{H}_{3} \mathrm{~B} \cdot \mathrm{NMe}_{3}$ to $\left[\mathrm{Rh}\left(\kappa^{3}\right.\right.$ $\left.\left.\mathrm{P}, \mathrm{O}, \mathrm{P}-\mathrm{Xantphos}-{ }^{\mathrm{t}} \mathrm{Bu}\right)(\mathrm{H})_{2}\right]\left[\mathrm{BAr}^{\mathrm{F}}{ }_{4}\right], \mathbf{1 0},{ }^{26 \mathrm{~b}}$ results in no observable amine-borane adduct (Eq. 1), although H/D exchange experiments (vide infra) suggest such a complex is accessible.

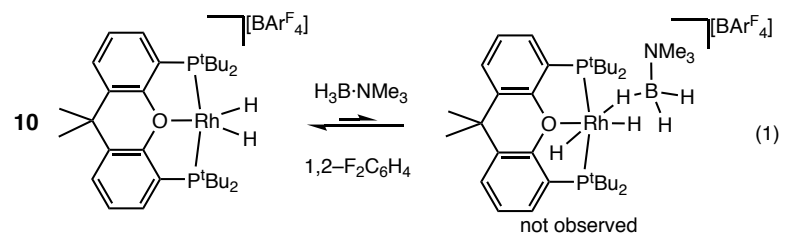

Complexes 5 and $\mathbf{6}$ do not lose $\mathrm{H}_{2}$ when exposed to a vacuum $\left(10^{-3}\right.$ Torr). It is thus likely that during catalysis the $\mathrm{Rh}(\mathrm{III})$ oxidation-state is persistent.

These cationic amine-borane complexes can alternatively be prepared by halide abstraction, using $\mathrm{Na}\left[\mathrm{BAr}_{4}^{\mathrm{F}}{ }_{4}\right.$, from a hydrido-chloride precursor $\mathrm{Rh}\left(\kappa^{3}-\mathrm{P}, \mathrm{O}, \mathrm{P}-\mathrm{X}\right.$ antphos $\left.-{ }^{\mathrm{i}} \mathrm{Pr}\right)(\mathrm{H})_{2} \mathrm{Cl}$,

Scheme 5. Halide abstraction route. $\left[\mathrm{BAr}^{\mathrm{F}}{ }_{4}\right]^{-}$anions are not shown.

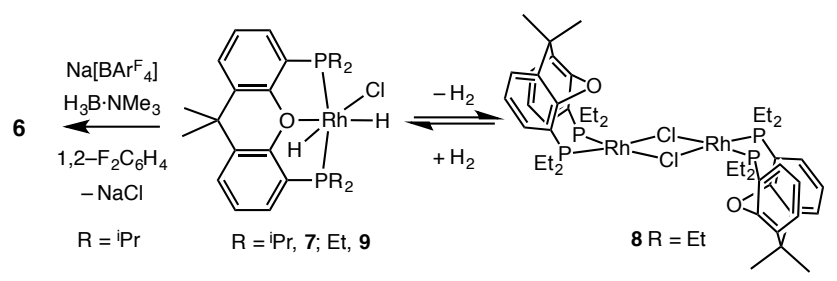


7, ${ }^{4 \mathrm{~d}, 26 \mathrm{~b}, 35}$ in the presence of $\mathrm{H}_{3} \mathrm{~B} \cdot \mathrm{NMe}_{3}$. Complex 6 can thus be prepared in $79 \%$ yield as a crystalline, analytically pure, solid (Scheme 5). By contrast, complex 5 cannot be prepared by this route. While addition of $\mathrm{H}_{2}$ to dimeric $\left[\mathrm{Rh}\left(\kappa^{2}-\mathrm{P}, \mathrm{P}-\mathrm{X}\right.\right.$ antphos$\mathrm{Et}) \mathrm{Cl}_{2} \quad \mathbf{8}$ (Supporting Materials) gives $\mathrm{Rh}\left(\kappa^{3}-\mathrm{P}, \mathrm{O}, \mathrm{P}-\right.$ Xantphos-Et $)(\mathrm{H})_{2} \mathrm{Cl}, \mathbf{9}$, this complex is only stable under an $\mathrm{H}_{2}$ atmosphere regenerating 8 on its removal. For the ${ }^{\mathrm{t}} \mathrm{Bu}$ analogue $\mathrm{Rh}\left(\kappa^{3}-\mathrm{P}, \mathrm{O}, \mathrm{P}-\mathrm{Xantphos}-{ }^{\mathrm{t}} \mathrm{Bu}\right) \mathrm{Cl}$ Goldman has calculated that $\mathrm{H}_{2}$ addition is favoured $\left(\Delta \mathrm{G}=-5 \mathrm{kcal} \mathrm{mol}^{-1}\right){ }^{26 \mathrm{~b}}$ Our observations suggest that the thermodynamics of $\mathrm{H}_{2}$ addition to 8 are more finely balanced, presumably as a consequence of the $\kappa^{2}-\mathrm{P}, \mathrm{P}-\mathrm{X}$ antphos-Et geometry being more accessible, which promotes a dimeric structure which has two $\mathrm{Cl}$ bonds per metal (as noted for related Os-systems ${ }^{27 d}$ ).

2.2 Neutral precursors One of the reasons that the Xantphos-R systems are so interesting to study in amineborane dehydropolymerization is that both cationic and neutral precursors are available with iso-propyl or tert-butyl groups; e.g. generically $\mathbf{D}$ and $\mathbf{F}$, Scheme 4 . While $\mathrm{Rh}\left(\kappa^{3}-\mathrm{P}, \mathrm{O}, \mathrm{P}-\right.$ Xantphos $\left.{ }^{\mathrm{i}} \mathrm{Pr}\right) \mathrm{H}, \mathbf{1 1}$, can be isolated in good yield, as reported by Esteruelas, ${ }^{4 d}$ it undergoes a very fast reaction with $1,2-$ $\mathrm{F}_{2} \mathrm{C}_{6} \mathrm{H}_{4}$ (the current solvent-of-choice used in our cationic systems) on time of mixing (Scheme 6) to form $\mathrm{C}-\mathrm{H}$ activated $\mathrm{Rh}\left(\kappa^{3}-\mathrm{P}, \mathrm{O}, \mathrm{P}-\mathrm{X}\right.$ antphos $\left.-{ }^{\mathrm{i}} \mathrm{Pr}\right)\left(2,3-\mathrm{F}_{2} \mathrm{C}_{6} \mathrm{H}_{3}\right)$ 12. A single crystal $\mathrm{X}$-ray diffraction analysis confirmed the structure. $\mathrm{C}-\mathrm{H}$ activation of fluoroarenes by $\mathbf{1 1}$ has been reported previously with $\mathrm{FC}_{6} \mathrm{H}_{5}$ and $1,3-\mathrm{F}_{2} \mathrm{C}_{6} \mathrm{H}_{4} \cdot{ }^{27 a}$ Complex 12 is thus likely the actual precatalyst when using this solvent. In contrast $\mathrm{Rh}\left(\kappa^{3}-\mathrm{P}, \mathrm{O}, \mathrm{P}-\right.$ Xantphos- $\left.-^{t} \mathrm{Bu}\right) \mathrm{H}, \mathbf{1 3}^{26 \mathrm{~b}}$ is more robust and does not react with $1,2-\mathrm{F}_{2} \mathrm{C}_{6} \mathrm{H}_{4}$. Attempts to prepare $\mathrm{Rh}\left(\kappa^{3}-\mathrm{P}, \mathrm{O}, \mathrm{P}-\mathrm{X}\right.$ antphosEt)H were unsuccessful.

Scheme 6. Neutral precatalysts.

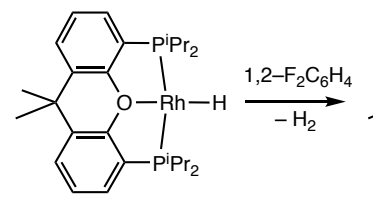

11

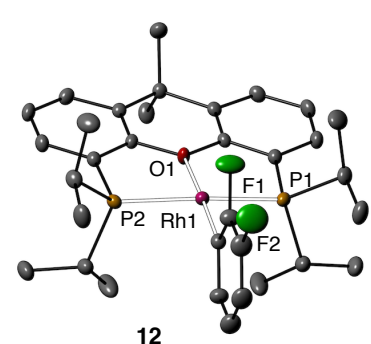

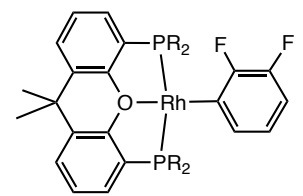

$12\left(\mathrm{R}={ }^{\mathrm{i}} \mathrm{Pr}\right)$

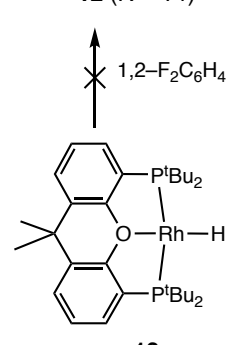

13
2.3 H/D exchange reactions These observations highlight the steric constraints the $\mathrm{P}$-alkyl groups place on $\mathrm{H}_{3} \mathrm{~B} \cdot \mathrm{NMe}_{3}$ coordination and related processes. As B-H activation at the metal center ${ }^{1 \mathrm{c}}$ is a key step in dehydrogenation we were interested in probing such events, without the complication of subsequent $\mathrm{N}-\mathrm{H}$ activation, by using $\mathrm{H}_{3} \mathrm{~B} \cdot \mathrm{NMe}_{3}$. Addition of excess $D_{2}$ to cationic complexes 5 or 6 resulted in $H / D$ exchange at both the $\mathrm{Rh}-\mathrm{H}$ and $\mathrm{BH}_{3}$ groups (5: $25 \% \mathrm{~B}-\mathrm{D}$ after 5 minutes, 6: $20 \%$ B-D after 5 minutes). Given that $\mathrm{H}_{2}$ loss from these complexes is not observed, H/D exchange likely operates through a sigma-complex-assisted metathesis $(\sigma-$ CAM) mechanism ${ }^{36}$ (I, Scheme 7) in a Rh(III) manifold, similar to $\left[\mathrm{M}\left(\mathrm{PCy}_{3}\right)_{2}(\mathrm{H})_{2}\left(\mathrm{H}_{3} \mathrm{~B} \cdot \mathrm{NMe}_{3}\right)\right]\left[\mathrm{BAr}_{4}^{\mathrm{F}}\right](\mathrm{M}=\mathrm{Rh}$, Ir $)$ com- plexes. ${ }^{33} \mathrm{H} / \mathrm{D}$ exchange also occurs in $\mathbf{1 0}$ when exposed to excess $\mathrm{D}_{3} \mathrm{~B} \cdot \mathrm{NMe}_{3}\left(20 \% \mathrm{RhD}_{2}\right.$ after 5 minutes $)$, showing that the borane must interact with the metal center, albeit at a low equilibrium concentration.

Scheme 7. H/D exchange in cationic and neutral complexes. $\left[\mathrm{BAr}^{\mathrm{F}}{ }_{4}\right]^{-}$anions are not shown.
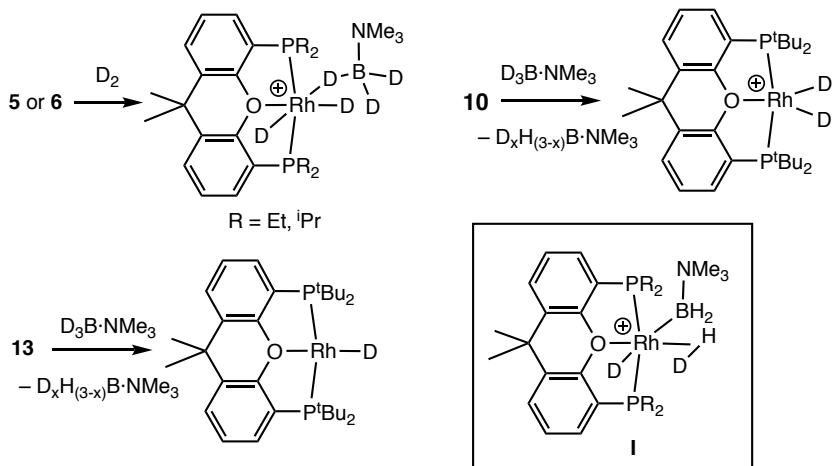

Although neutral $\mathbf{1 3}$ does not form a complex with $\mathrm{H}_{3} \mathrm{~B} \cdot \mathrm{NMe}_{3}$ it does undergo $\mathrm{H} / \mathrm{D}$ exchange with $\mathrm{D}_{3} \mathrm{~B} \cdot \mathrm{NMe}_{3}$ in $1,2-\mathrm{F}_{2} \mathrm{C}_{6} \mathrm{H}_{4}$ solution to form the corresponding deuteride $(10 \%$ after 10 minutes). Reactivity of 11 with $\mathrm{D}_{3} \mathrm{~B} \cdot \mathrm{NMe}_{3}$ in $1,2-\mathrm{F}_{2} \mathrm{C}_{6} \mathrm{H}_{4}$ solution is frustrated by the rapid formation of $\mathbf{1 2}$. These observations show that, where measureable, all the cationic and neutral complexes undergo reversible $\mathrm{B}-\mathrm{H}$ activation at the metal center.

2.4 Initial catalyst screening Table 1 summarizes $\mathrm{H}_{3} \mathrm{~B} \cdot \mathrm{NMeH}_{2}$ dehydropolymerization screening experiments, and demonstrates the influence of the sterics and charge of the $\{\mathrm{Rh}($ Xantphos-R $)\}$ fragment. These experiments were performed under conditions used previously $(0.2 \mathrm{~mol} \%$ catalyst, $0.446 \mathrm{M} \mathrm{H}_{3} \mathrm{~B} \cdot \mathrm{NMeH}_{2}$, system open to a flow of $\mathrm{Ar}, 1,2$ $\mathrm{F}_{2} \mathrm{C}_{6} \mathrm{H}_{4}$ solvent $^{5 \mathrm{~b}}$ ). Notable is that both cationic (6) and neutral (11) Xantphos- ${ }^{i} P r$ catalysts promote high conversions to $\left(\mathrm{H}_{2} \mathrm{BNMeH}\right)_{\mathrm{n}}$ (greater than $\left.90 \%\right)$ in short reaction times (less than 30 minutes), as signalled by a distinctive broad resonance observed at ca. $\delta-5.1\left(1,2-\mathrm{F}_{2} \mathrm{C}_{6} \mathrm{H}_{4}\right)$ in the ${ }^{11} \mathrm{~B}$ NMR spectrum. $^{2 \mathrm{~d}, 4 \mathrm{a}, 5 \mathrm{~b}}$ Only small amounts of $N$-trimethylborazine, $(\mathrm{HBNMe})_{3}[\delta 33.2, \mathrm{~d}, J(\mathrm{BH})=132 \mathrm{~Hz}]^{11 \mathrm{a}}$ were observed. Xantphos- ${ }^{t} \mathrm{Bu}$ systems (10 and $\mathbf{1 3}$ respectively) are slower (hours), produce more (HBNMe) $)_{3} /$ other dehydrocoupling side products and less isolated polymer. At $10 \mathrm{~mol} \%$ the major product with catalysts $\mathbf{6}$ and $\mathbf{1 1}$ was $N$-trimethylborazine. Changing solvent to THF (which has previously been used as a solvent for 11 in dehydrogenation of $\mathrm{H}_{3} \mathrm{~B} \cdot \mathrm{NH}_{3}{ }^{28}$ ) resulted in low conversions and a slow reaction for cationic catalyst 6 ( $40 \%$ conversion after 3 hours). We postulate that this is due to the formation of the cationic THF-adduct $\left[\mathrm{Rh}\left(\kappa^{3}-\mathrm{P}, \mathrm{O}, \mathrm{P}-\right.\right.$ Xantphos-R)(H $\left.)_{2}(\mathrm{THF})\right]\left[\mathrm{BAr}_{4}{ }_{4}\right]$ in which the THF binds strongly with the $\mathrm{Rh}$-center, thus attenuating amine-borane dehydrogenation. Complex 5 (Xantphos-Et) is a very slow catalyst, only converting $27 \% \mathrm{H}_{3} \mathrm{~B} \cdot \mathrm{NMeH}_{2}$ to polymer after 15 hours. Xantphos- ${ }^{\text {i }}$ Pr pre-catalysts 6 and 11 thus offered the best opportunity to study the kinetics of dehydropolymerization and catalyst control over the resulting polymer using 1,2$\mathrm{F}_{2} \mathrm{C}_{6} \mathrm{H}_{4}$ solvent. We concentrate on these two systems, but return to Xantphos- ${ }^{\mathrm{t}} \mathrm{Bu}$ and Xantphos-Et to allow for wider comparisons.

2.5 Dehydropolymerization: molecular weight determinations, entrained catalyst and polymer growth kinetics. Offwhite polyaminoborane $\left(\mathrm{H}_{2} \mathrm{BNMeH}\right)_{n}$, can be isolated in 
Table 1: Catalyst screening for $\mathrm{H}_{3} \mathrm{~B} \cdot \mathrm{NMeH}_{2}$ dehydropolymerization. Conditions: $\left[\mathrm{H}_{3} \mathrm{~B} \cdot \mathrm{NMeH}_{2}\right]=0.446 \mathrm{M}$; cat. $=0.2 \mathrm{~mol} \%$; solvent $=1,2-\mathrm{F}_{2} \mathrm{C}_{6} \mathrm{H}_{4}$. Flask open to a flow of argon.

\begin{tabular}{cccll}
\hline Catalyst & Conversion $^{\mathrm{a}}$ & Time $^{2}$ mins $^{\mathrm{b}}$ & \multicolumn{1}{c}{ Products $^{\mathrm{c}}$} & \multicolumn{1}{c}{ Isolated Yield $^{\mathrm{d}}$} \\
\hline $\mathbf{5}$ & $37 \%$ & 900 & $\left(\mathrm{H}_{2} \mathrm{BNMeH}\right)_{\mathrm{n}}(27 \%)$, other $(10 \%)$ & $8 \%$ \\
$\mathbf{6}$ & $98 \%$ & 20 & $\left(\mathrm{H}_{2} \mathrm{BNMeH}\right)_{\mathrm{n}}(93 \%),(\mathrm{HBNMe})_{3}(5 \%)$ & $63 \%$ \\
$\mathbf{1 0}$ & $87 \%$ & 360 & $\left(\mathrm{H}_{2} \mathrm{BNMeH}\right)_{\mathrm{n}}(76 \%)$, other $(11 \%)$ & $30 \%$ \\
$\mathbf{1 1}$ & $94 \%$ & 30 & $\left(\mathrm{H}_{2} \mathrm{BNMeH}\right)_{\mathrm{n}}(93 \%),(\mathrm{HBNMe})_{3}(1 \%)$ & $65 \%$ \\
$\mathbf{1 3}$ & $90 \%$ & 270 & $\left(\mathrm{H}_{2} \mathrm{BNMeH}\right)_{\mathrm{n}}(70 \%),(\mathrm{HBNMe})_{3}(11 \%)$, other $(9 \%)$ & $20 \%$ \\
\hline
\end{tabular}

${ }^{\text {a }}$ Conversion of $\mathrm{H}_{3} \mathrm{~B} \cdot \mathrm{NMeH}_{2}$ as measured by ${ }^{11} \mathrm{~B}$ NMR spectroscopy. ${ }^{\mathrm{b}}$ Unoptimized. ${ }^{\mathrm{c}}$ As determined by ${ }^{11} \mathrm{~B}$ NMR spectroscopy of the reaction solution. ${ }^{\mathrm{d}}$ Isolated by precipitation into hexane.

yields of up to $65 \%$ ( $0.7 \mathrm{~g}$ scale $)$ using precatalysts 6 and 11 . The ${ }^{11} \mathrm{~B}$ NMR spectra of isolated polymer produced by either catalyst are similar, showing a broad peak, centered around $\delta$ $5\left(\mathrm{CD}_{2} \mathrm{Cl}_{2}\right)$, Figure 3. A small shoulder is also apparent at ca. 2 ppm that may be indicative of a small amount of chainbranching (i.e. "BN $\mathrm{B}_{3}$ " or " $\mathrm{BN}_{4}$ " in the polymer backbone). ${ }^{4 \mathrm{e}, 37}$ A signal to lower field has previously been shown to be particularly distinct in cases where chain-branching is proposed. ${ }^{15}$ A small signal at $\delta-17.6$ suggests some entrained $\mathrm{H}_{3} \mathrm{~B} \cdot \mathrm{NMeH}_{2}$, although this might also be masking a broader $\mathrm{BH}_{3}$ polymer end group signal. The ${ }^{1} \mathrm{H}$ NMR spectra show environments assigned to $\mathrm{NH}, \mathrm{NMe}$ and $\mathrm{BH}_{2}$, and are very similar for polymer from each catalyst. A small shoulder on the NMe signal is observed to low field, but this is poorly resolved. The ${ }^{13} \mathrm{C}\left\{{ }^{1} \mathrm{H}\right\}$ NMR spectra are also similar for both polymeric materials, and show multiple environments assigned to $\mathrm{NMe}$. In polymer derived from $\mathbf{6}$ a sharper signal is observed at $\delta 36.2$, which resolves into two signals for polymer derived from 11 ( $\delta 36.2,36.1)$. Much broader, lower field, signals are observed for both polymer samples centerd at ca. $\delta$ 37 . Very similar spectral data have been observed for $\mathrm{N}-$

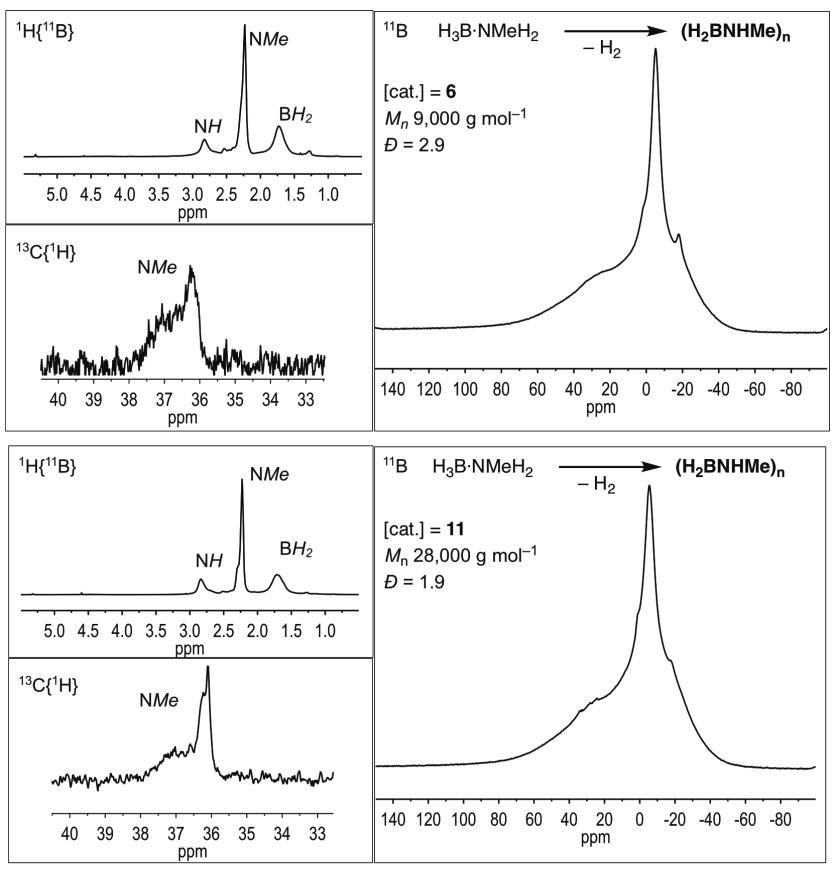

Figure 3. Selected NMR spectra $\left(\mathrm{CD}_{2} \mathrm{Cl}_{2}, 298 \mathrm{~K}\right)$ for isolated polyaminoborane produced by catalyst 6 (top) and catalyst 11 (bottom): $0.2 \mathrm{~mol} \%, 0.446 \mathrm{M} \mathrm{H}_{3} \mathrm{~B} \cdot \mathrm{NMeH}_{2}$. The broad baseline signal observed in the ${ }^{11} \mathrm{~B}$ NMR spectra at ca. $20 \mathrm{ppm}$ is due to background from tube and probe (borosilicate glass). methyl polyaminoborane produced using $\operatorname{Ir}(\mathrm{POCOP})(\mathrm{H})_{2}{ }^{4 \mathrm{a}}$ and (PNHP)Fe( $\mathrm{H})(\mathrm{CO})\left(\mathrm{HBH}_{3}\right){ }^{6}$, especially the multiple environments in the ${ }^{13} \mathrm{C}\left\{{ }^{1} \mathrm{H}\right\}$ NMR spectra. The ${ }^{13} \mathrm{C}\left\{{ }^{1} \mathrm{H}\right\}$ NMR spectrum of, related, polyphosphino-borane $\left(\mathrm{H}_{2} \mathrm{BP}^{t} \mathrm{BuH}\right)_{\mathrm{n}}$ formed by a thermal dehydropolymerization $\left(M_{\mathrm{n}} \sim 30,000 \mathrm{~g} \mathrm{~mol}^{-1}, Ð \sim\right.$ $1.8),{ }^{13 \mathrm{~b}}$ also shows multiple environments for the ${ }^{\mathrm{t}} \mathrm{Bu}$ group, not dissimilar to those observed here for the NMe groups; while in the ${ }^{31} \mathrm{P}$ NMR spectra multiple environments are also observed. The latter were interpreted as being due to the tactic environments associated with the polymer, and in particular specific triads. A mixture of $R, R$ and $R, S$ diastereoisomers of the linear triborazane $\mathrm{H}_{3} \mathrm{~B}\left(\mathrm{NMeHBH}_{2}\right)_{2} \mathrm{NMeH}_{2}$ have also been synthesized, although no ${ }^{13} \mathrm{C}$ NMR data were reported. ${ }^{38} \mathrm{We}$ are reluctant interpret our current data further with regard to polymer stereochemistry, especially given the possibility for additional chain-branching. Nevertheless, taken together, these spectral observations could well be important in future studies of polyaminoborane tacticity.

Analysis by gel permeation chromatography (GPC, polystyrene standards, refractive index (RI) detector) of polymer produced using cationic 6 showed what appeared, at first inspection, to be a bimodal distribution of polymer molecular weights (Figure 4A, solid-line), in which a broad low intensity peak characteristic of $\left(\mathrm{H}_{2} \mathrm{BNMeH}\right)_{n}{ }^{4 a}$ was augmented with a
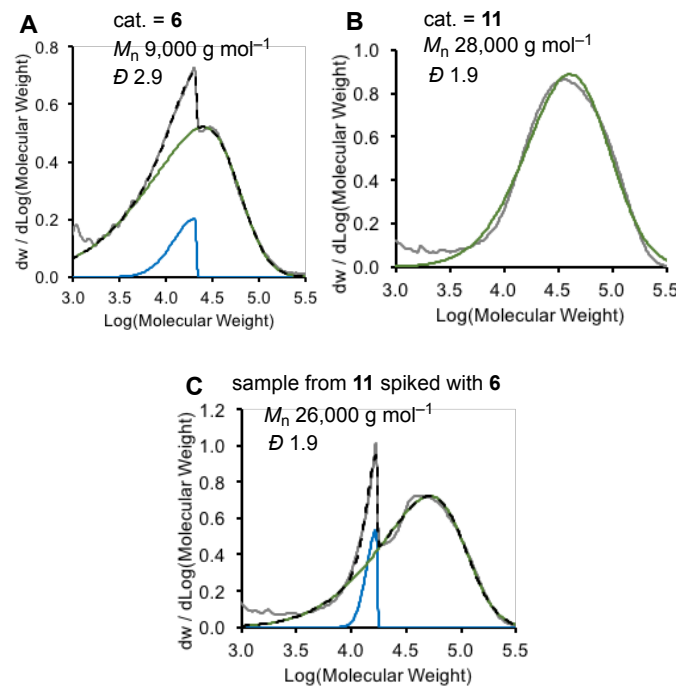

Figure 4. Experimental (grey, solid-line), combined fitted (black, dashed) and individual skewed Gaussian fits (green and blue, solid) GPC data for polyaminoborane produced using: (A) Cationic catalyst $6\left(0.2 \mathrm{~mol} \%, 0.446 \mathrm{M} \mathrm{H}_{3} \mathrm{~B} \cdot \mathrm{NMeH}_{2}\right)$; (B) Neutral catalyst $11\left(0.2 \mathrm{~mol} \%, 0.446 \mathrm{M} \mathrm{H}_{3} \mathrm{~B} \cdot \mathrm{NMeH}_{2}\right) ;(\mathbf{C})$ Neutral catalyst 11, spiked post catalysis with $0.2 \mathrm{~mol} \% \mathbf{6}$ (conditions as for B). 
a sharper peak that displayed with a tail to lower $M_{\mathrm{n}}$. Significantly, this signal was absent in polymer produced using neutral catalyst 11 (Figure 4B), and we suspected it may be due to $\left[\mathrm{BAr}_{4}^{\mathrm{F}}\right]^{-}$entrained in the polymer. Even though the catalyst is used in low concentration $(0.2 \mathrm{~mol} \%)$ the $\left[\mathrm{BAr}^{\mathrm{F}}{ }_{4}\right]^{-}$aryl groups would be expected to be significantly more sensitive to RI detection than polyaminoborane, a technique that has been shown to have a positive correlation to the polarizability of any functional group. ${ }^{39}{ }^{19} \mathrm{~F}$ NMR spectroscopy of polymer produced using $\mathbf{6}$, showed a signal at $\delta-63.2$ consistent with $\left[\mathrm{BAr}_{4}^{\mathrm{F}}\right]^{-}$, while for that from $\mathbf{1 1}$ this signal was absent. In the ${ }^{1} \mathrm{H}$ NMR spectrum of polymer derived from catalyst $\mathbf{6}$ signals assigned to $\mathrm{C}_{6} \mathrm{H}_{3}\left(\mathrm{CF}_{3}\right)_{2}$ were observed, and when integrated with respect to the $\mathrm{BNMe}$ signal a loading of $0.18 \mathrm{~mol} \%$ was measured. ICP-MS analysis for $\mathrm{Rh}$-content from these polymer samples indicated a loading of $\sim 450 \mathrm{ppm}$ (i.e. 0.045 mol\%), suggesting that the anion and cation are both entrained, albeit to differing extents. Neutral catalyst 11 showed higher levels of $\mathrm{Rh}$-incorporation, $1200 \mathrm{ppm}(0.12 \mathrm{~mol} \%)^{40}$ Final evidence that this extra GPC peak comes from $\left[\mathrm{BAr}_{4}^{\mathrm{F}}\right]^{-}$ came from spiking a sample of polymer produced using catalyst 11 with $0.2 \mathrm{~mol} \% 6$ which showed the characteristic skewed GPC signal (Scheme 4C). These signals for $\left[\mathrm{BAr}_{4}^{\mathrm{F}}\right]^{-}$ were not reduced by re-precipitation of the polymer suggesting that the $\left[\mathrm{BAr}_{4}^{\mathrm{F}}\right]^{-}$anion may be associated with the polymer. ${ }^{41}$ A similar entrainment of catalyst in phosphine-borane dehydropolymerization has recently been reported. ${ }^{13 \mathrm{e}}$ The GPC traces were deconvoluted ${ }^{42}$ using a skewed Gaussian bimodal distribution using a stand-alone programme. These gave acceptable fits to the data. ${ }^{43}$ Importantly, using these fits the molecular weight and dispersity data for the spiked samples from neutral catalyst 11 recover the unspiked data well giving confidence in the approach.

These data show a significant difference between the polymer produced with the two catalysts under these conditions, even though the NMR data are similar for both. Cationic 6 produces polyaminoborane of low molecular weight and high dispersity (e.g. $M_{\mathrm{n}}=9,000 \mathrm{~g} \mathrm{~mol}^{-1}, Ð=2.9$ ) while neutral 11 produces higher molecular weight polymer with a more uniform distribution (e.g. $M_{\mathrm{n}}=28,000 \mathrm{~g} \mathrm{~mol}^{-1}, Ð=1.9$ ). The effect of time (i.e. conversion), catalyst loading, and catalyst identity was probed in more detail, using raw GPC data for $\mathbf{1 1}$ and modelled GPC data for $\mathbf{6}$, as shown in Figure 5 and Table 2.

For cationic catalyst 6 a plot of $M_{\mathrm{n}}$ versus conversion of $\mathrm{H}_{3} \mathrm{~B} \cdot \mathrm{NMeH}_{2}$ to polyaminoborane (as measured by ${ }^{11} \mathrm{~B} \mathrm{NMR}$ spectroscopy for individual samples quenched at the appropriate point by addition of excess $\mathrm{PPh}_{3}{ }^{44}$ ) revealed that at low conversion polymer of appreciable molecular weight was being formed $\left(M_{\mathrm{n}}=10,000 \mathrm{~g} \mathrm{~mol}^{-1}, Ð=2.0\right)$, and this did not change significantly over the course of dehydropolymerization, Figure 5A. At these low conversions $\mathrm{H}_{3} \mathrm{~B} \cdot \mathrm{NMeH}_{2}$ is the dominant species by ${ }^{11} \mathrm{~B}$ NMR spectroscopy, while the signal at ca. $\delta-5$ assigned to polyaminoborane is broad and gives no indication that short chain oligomers (e.g. $\mathrm{H}_{3} \mathrm{~B} \cdot \mathrm{NMeHBH} \mathrm{NMeH}_{2}$ ) are being formed, as these would be expected to show more resolved B-H coupling. .b,12a $^{-}$

These data are broadly consistent with controlled ${ }^{19}$ chaingrowth polymer propagation, in which a reactive aminoborane monomer undergoes rapid head-to-tail polymerization to give $\left(\mathrm{H}_{2} \mathrm{BNMeH}\right)_{\mathrm{n}}{ }^{45}$ followed by termination. If this occurred via a coordination-insertion-type mechanism at a metal center, reducing the catalyst loading would be expected
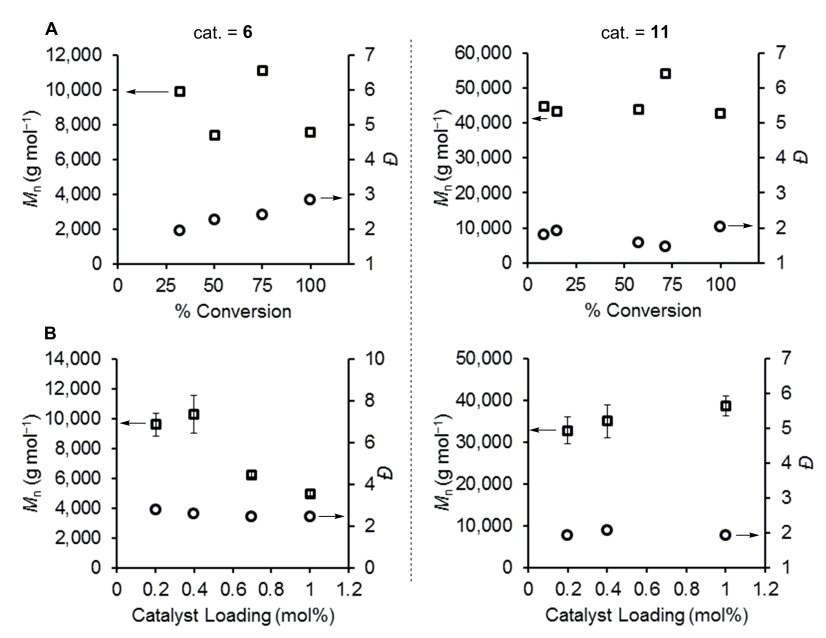

Figure 5. $\left(\mathrm{H}_{2} \mathrm{BNMeH}\right)_{n}$ polymer growth kinetics using catalysts 6 and 11. $M_{\mathrm{n}}$ and dispersity $(\oslash)$ data derived from skewed Gaussian fits for 6. Measured from a system open to $\mathrm{Ar}$ flow. $\left[\mathrm{H}_{3} \mathrm{~B} \cdot \mathrm{NMeH}_{2}\right]=0.446 \mathrm{M}$. (Top) $M_{\mathrm{n}}\left(\mathrm{g} \mathrm{mol}^{-1}\right)$ versus conversion, conversion measured by ${ }^{11} \mathrm{~B}$ NMR spectroscopy, samples quenched by addition of excess (5 equivalents) $\mathrm{PPh}_{3}$; (Bottom) $M_{\mathrm{n}}\left(\mathrm{g} \mathrm{mol}^{-1}\right)$ versus [cat.] at $100 \%$ conversion. Errors determined by repeat polymerizations.

to increase the degree of polymerization, as noted for dehydropolymerizations of $\mathrm{H}_{3} \mathrm{~B} \cdot \mathrm{NMeH}_{2}$ using catalyst 1 , ${ }^{5 \mathrm{~b}}$ and $\mathrm{H}_{3} \mathrm{~B} \cdot \mathrm{PPhH}_{2}$ using $\mathrm{Fe}\left(\eta^{5}-\mathrm{C}_{5} \mathrm{H}_{5}\right)(\mathrm{CO})_{2}(\mathrm{OTf}) .{ }^{13 \mathrm{~d}}$ Figure $5 \mathrm{~B}$ shows that increasing the catalyst loading from $0.2 \mathrm{~mol} \%$ to 1 $\mathrm{mol} \%$ for 6 results in a decrease in polymer molecular weight: $M_{\mathrm{n}}=5,000 \mathrm{~g} \mathrm{~mol}^{-1}(\bigoplus=2.4)$. Within the confidence limits of polyaminoborane analysis, exacerbated by the low molecular weight polymer tailing into the intrinsic system peaks associated with GPC analysis, we consider this trend to be weak at best and we suggest that this data does not strongly support a coordination-insertion mechanism. As we discuss (Section 2.6), we cannot discount that this trend also reflects trace impurities in the solvent that might disproportionally modify catalyst concentration at low loadings. Catalyst $\mathbf{1 1}$ shows an opposite, but still weak, relationship between catalyst loading and $M_{\mathrm{n}}$ in which increased loadings lead to slightly increased degrees of polymerization: $0.2 \mathrm{~mol} \%\left(M_{\mathrm{n}}=33,000 \mathrm{~g} \mathrm{~mol}^{-1}, Ð\right.$ $=1.9)$ versus $1 \mathrm{~mol} \%$ loadings $\left(M_{\mathrm{n}}=39,000 \mathrm{~g} \mathrm{~mol}^{-1}, Ð=1.9\right)$. An increase in molecular weight of isolated polymer on increasing catalyst loading has been noted for $\operatorname{Ir}(\mathrm{POCOP})(\mathrm{H})_{2}$, $\mathbf{A} ;{ }^{4 a}$ while, for catalyst $\mathbf{B}$ changes in catalyst loading can induce small molecular weight changes in either direction depending on the solvent used. ${ }^{6}$ For catalyst 11 a degree of polymerization (i.e. $M_{\mathrm{n}}$ ) versus conversion plot also indicates a chain-growth type process is in operation (Fig. 5A).

Addition of two successive batches of $\mathrm{H}_{3} \mathrm{~B} \cdot \mathrm{NMeH}_{2}$ to catalysis solutions post dehydropolymerization $(0.2 \mathrm{~mol} \% \mathbf{6}$ or $\mathbf{1 1}$, $\left.0.446 \mathrm{M}\left[\mathrm{H}_{3} \mathrm{~B} \cdot \mathrm{NMeH}_{2}\right]\right)$ resulted in full consumption of $\mathrm{H}_{3} \mathrm{~B} \cdot \mathrm{NMeH}_{2}(\mathrm{TON}=1,500)$, but no significant change in the molecular weight of isolated polymer $\left(\mathbf{6}: M_{\mathrm{n}}=15,000 \mathrm{~g} \mathrm{~mol}^{-1}\right.$, $\left.Ð=1.9 ; 11: M_{\mathrm{n}}=26,000 \mathrm{~g} \mathrm{~mol}^{-1}, Ð=2.3\right)$. This indicates that the systems are not living, ${ }^{19,46}$ but also that species present at the end of catalysis are still active for dehydropolymerization and can be recharged (Section 2.7.1).

Table 2 additionally provides representative results from a study of concentration, exogenous cyclohexene as a potential modifier to control polymer molecular weight. For catalyst 6 
Table 2. Representative polymer molecular weights $\left(\mathrm{g} \mathrm{mol}^{-1}\right)$ and dispersity data.

\begin{tabular}{|c|c|c|c|c|c|}
\hline Entry & Catalyst & {$\left[\mathrm{H}_{3} \mathrm{~B} \cdot \mathrm{NMeH}_{2}\right] / \mathrm{M}$} & [cat.] /M (mol\%) & $M_{\mathrm{n}} / \mathrm{g} \mathrm{mol}^{-1}$ & $D$ \\
\hline 1 & $6^{\mathrm{a}}$ & 0.446 & $8.92 \times 10^{-4}(0.2)$ & 9,500 & 2.8 \\
\hline 2 & $6^{\mathrm{a}}$ & 0.446 & $4.46 \times 10^{-3}(1.0)$ & 5,000 & 2.4 \\
\hline 3 & $6^{\mathrm{b}}$ & 0.446 & $8.92 \times 10^{-4}(0.2)$ & 8,500 & 2.7 \\
\hline 4 & $6^{\mathrm{a}}$ & 0.223 & $4.46 \times 10^{-4}(0.2)$ & 13,000 & 2.5 \\
\hline 5 & $6^{\mathrm{a}}$ & 0.1115 & $2.23 \times 10^{-4}(0.2)$ & 13,500 & 2.5 \\
\hline 6 & $6^{\mathrm{a}}$ & 0.1115 & $1.115 \times 10^{-4}(1.0)$ & 5,000 & 2.4 \\
\hline 7 & $6^{\mathrm{b}}$ & 0.223 & $4.46 \times 10^{-4}(0.2)$ & 10,000 & 2.2 \\
\hline 8 & $6^{\mathrm{d}}$ & 0.223 & $4.46 \times 10^{-4}(0.2)$ & 9,000 & 2.5 \\
\hline 9 & $6^{c}$ & 0.223 & $4.46 \times 10^{-4}(0.2)$ & 12,000 & 2.4 \\
\hline 10 & $11^{\mathrm{a}}$ & 0.446 & $8.92 \times 10^{-4}(0.2)$ & 39,000 & 2.1 \\
\hline 11 & $11^{\mathrm{b}}$ & 0.446 & $8.92 \times 10^{-4}(0.2)$ & 33,000 & 2.1 \\
\hline 12 & $11^{\mathrm{b}}$ & 0.446 & $4.46 \times 10^{-3}(1.0)$ & 39,000 & 1.9 \\
\hline 13 & $11^{\mathrm{d}}$ & 0.446 & $8.92 \times 10^{-4}(0.2)$ & 28,000 & 2.1 \\
\hline 14 & $11^{\mathrm{c}}$ & 0.446 & $8.92 \times 10^{-4}(0.2)$ & 33,000 & 1.8 \\
\hline 15 & $11^{b}$ & 0.223 & $4.46 \times 10^{-4}(0.2)$ & 17,000 & 2.0 \\
\hline 16 & $6^{a}$ & $0.446 \times 3$ & $8.92 \times 10^{-4}(0.2)$ & 15,000 & 1.9 \\
\hline 17 & $11^{\mathrm{a}}$ & $0.446 \times 3$ & $8.92 \times 10^{-4}(0.2)$ & 26,000 & 2.3 \\
\hline
\end{tabular}

${ }^{\mathrm{a}}$ Under $\mathrm{H}_{2}$ evolution measurement conditions connected to a gas burette. ${ }^{\mathrm{b}}$ Under a flow of Ar. ${ }^{\mathrm{c}}$ Under a flow of Ar in the presence of 2.7 equivalents (relative to $\mathrm{H}_{3} \mathrm{~B} \cdot \mathrm{NMeH}_{2}$ ) of cyclohexene. ${ }^{\mathrm{d}}$ A closed system allowing for $\mathrm{H}_{2}$ build-up.

concentration has no significant effect on molecular weight within the confidence limits of polymer analysis (compare entries 3 and 7). For catalyst $\mathbf{1 1}$ a reduction in concentration to $0.223 \mathrm{M}$ results in a decrease in molecular weight, $M_{\mathrm{n}}=$ $17,000 \mathrm{~g} \mathrm{~mol}^{-1}(Ð=1.6)$, entries 11 and $15 . \mathrm{H}_{2}$ does not act to significantly modify the chain length for either catalyst when allowed to build up in a closed system, or under the conditions of measuring $\mathrm{H}_{2}$ evolution using a gas burette, when compared with a system open to a flow of argon. Addition of 2.7 equivalents of cyclohexene (i.e. $270 \mathrm{~mol} \%$ ) to either catalyst (6 or 11) at $0.2 \mathrm{~mol} \%$ did not change the degree of polymerization significantly nor resulted in the observation of $\mathrm{Cy}_{2} \mathrm{~B}=\mathrm{NMeH}$ $\left[\delta\left({ }^{11} \mathrm{~B}\right) 44.9 \text {, br }(\mathrm{THF})\right]^{17 \mathrm{a}}$ - the product of hydroboration that potentially signals free $\mathrm{H}_{2} \mathrm{~B}=\mathrm{NMeH} .{ }^{\text {le }}$ At $10 \mathrm{~mol} \%$, where $(\mathrm{HBNMe})_{3}$ becomes the major product (vide supra), trace $\mathrm{Cy}_{2} \mathrm{~B}=\mathrm{NMeH}$ is observed using catalyst $6\left[\sim 1 \%, \delta\left({ }^{11} \mathrm{~B}\right) 45.9\right.$, $\left.1,2-\mathrm{F}_{2} \mathrm{C}_{6} \mathrm{H}_{4}\right]$ (Scheme 8). For catalyst 11 under the same conditions no hydroboration product is observed. These data suggest that any $\mathrm{H}_{2} \mathrm{~B}=\mathrm{NMeH}$ formed is consumed significantly faster in chain propagation/borazine formation rather than hydroboration, as has been commented upon previously. ${ }^{1 \mathrm{~d}, 4 \mathrm{e}, 47}$ Hydroboration of cyclohexene by transient $\mathrm{H}_{2} \mathrm{~B}=\mathrm{NMeH}$ has been reported in metal- free polymerizations, ${ }^{15}$ and in slower metal-promoted dehydropolymerizations. ${ }^{6}$ We have not observed $\mathrm{H}_{2} \mathrm{~B}=\mathrm{NMeH}$ in any in situ NMR experiments [lit. $\left.\delta\left({ }^{11} \mathrm{~B}\right) 37.1, \mathrm{t}, J(\mathrm{BH})=130\left(\mathrm{Et}_{2} \mathrm{O},-10^{\circ} \mathrm{C}\right)\right] .{ }^{15}$

The use of $\mathrm{H}_{2}$ as a chain termination agent is well established in olefin polymerization, and likely operates through sigmabond metathesis of $\mathrm{H}_{2}$ with the [M]- $\mathrm{CH}_{2}-\mathrm{R}$ growing polymer chain to form a metal hydride and free polymer. ${ }^{14,48}$ This lack of sensitivity to $\mathrm{H}_{2}$ for catalysts $\mathbf{6}$ and $\mathbf{1 1}$ is in contrast to catalyst $\mathbf{1}$ that shows a significant attenuation of molecular weight with $\mathrm{H}_{2}$, but is similar to $\mathbf{A}^{4 \mathrm{a}}$ and $\mathbf{B}^{6}$ where no significant
Scheme 8. Trapping experiments.

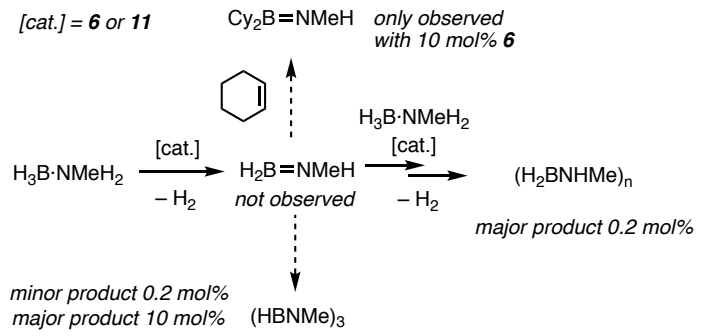

effects were reported. Catalyst 1 was suggested to operate via a coordination-insertion mechanism in which a nascent aminoborane, formed by dehydrogenation, inserts into a polymer chain that is propagating from the metal center via a covalent $\mathrm{Rh}-\mathrm{NHMeBH}_{2} \mathrm{R}$ (or $\mathrm{Rh}-\mathrm{BH}_{2} \mathrm{NMeHR}$ ) bond and is thus susceptible to hydrogenolysis, Scheme 3 . The lack of $\mathrm{H}_{2}$ sensitivity of 6 and 11, when combined with the relative insensitivity of polymer molecular weight to catalyst loading suggests a polymerization process where polymer propagation follows a classical chain-growth profile, rather than a coordinationinsertion mechanism. An alternative mechanism is one of step-growth which, characteristically, only shows higher molecular weight polymer being formed at very high conversions. ${ }^{45}$ Such behaviour has been suggested for the dehydropolymerization of $\mathrm{H}_{3} \mathrm{~B} \cdot \mathrm{PRH}_{2}(\mathrm{R}=\mathrm{Ph})$ using $\mathrm{Rh}$-based catalysts, ${ }^{13 c, 49}$ and can be explained by a facile reversible chain transfer between bound growing oligomer chains and $\mathrm{H}_{3} \mathrm{~B} \cdot \mathrm{PRH}_{2}$. Similar chain transfer behaviour has been noted for very slow amine-borane dehydrocoupling using the $\left[\operatorname{Ir}\left(\mathrm{PCy}_{3}\right)_{2}(\mathrm{H})_{2}\left(\mathrm{H}_{2}\right)_{2}\right]\left[\mathrm{BAr}_{4}{ }_{4}\right]$ catalyst. $^{11 \mathrm{c}, 12 \mathrm{a}}$ We discount that such a mechanism is operating here, as at early conversions for both catalysts $\mathbf{6}$ and $\mathbf{1 1} \mathrm{H}_{3} \mathrm{~B} \cdot \mathrm{NMeH}_{2}$ is still the major component, no short chain oligomers are observed in significant 
quantities (e.g. $\mathrm{H}_{3} \mathrm{~B} \cdot \mathrm{NMeHBH}_{2} \cdot \mathrm{NMeH}_{2}{ }^{12 \mathrm{a}}$ ) and the molecular weight of polymer isolated remains approximately constant throughout the reaction.

2.6 $\mathrm{H}_{2}$ evolution studies and the kinetic model. By following the evolution of $\mathrm{H}_{2}$ during dehydropolymerization, the dehydrogenation of $\mathrm{H}_{3} \mathrm{~B} \cdot \mathrm{NMeH}_{2}$ to form transient aminoborane, $\mathrm{H}_{2} \mathrm{~B}=\mathrm{NMeH}^{15}$ can be indirectly interrogated. For catalysts 6 and 11 close to one equivalent of $\mathrm{H}_{2}$ is released during dehydropolymerization, consistent with the small, less than $10 \%$, amount of $(\mathrm{HBNMe})_{3}$ formed. This means that the $\mathrm{H}_{2}$ evolved can be used as an effective proxy for $\mathrm{H}_{2} \mathrm{~B}=\mathrm{NMeH}$ generation which subsequently undergoes fast polymerisation. Figure $6 \mathrm{~A}$ shows a number of $\mathrm{H}_{2}$ evolution experiments using catalyst 6 in which both the concentration of $\mathrm{H}_{3} \mathrm{~B} \cdot \mathrm{NMeH}_{2}$ and catalyst is varied. For all regimes a small induction period was observed (20 - 90 seconds, not shown - Supporting Materials) that is variable between batches of $1,2-\mathrm{F}_{2} \mathrm{C}_{6} \mathrm{H}_{4}$ solvent, but consistent within each batch for repeat runs, as are the temporal profiles for $\mathrm{H}_{2}$ evolution. We, and others, have recently commented upon the presence of trace impurities in fluorinated arene solvents, ${ }^{50}$ and a $\mathrm{GC}-\mathrm{MS}$ analysis of $1,2-\mathrm{F}_{2} \mathrm{C}_{6} \mathrm{H}_{4}$ stirred over $\mathrm{Al}_{2} \mathrm{O}_{3}$ for one hour and vacuumed distilled from $\mathrm{CaH}_{2}$ showed trace quantities of $\mathrm{FClC}_{6} \mathrm{H}_{4}$ and $\mathrm{F}(\mathrm{OH}) \mathrm{C}_{6} \mathrm{H}_{4}$. We suggest that trace impurities, such as these, act to modify a small portion of catalyst in both the induction period and during productive catalysis. For this reason the data shown in Figure 6A comes from using the same batch of $1,2-\mathrm{F}_{2} \mathrm{C}_{6} \mathrm{H}_{4}$. Notably, isolated polymer does not vary in molecular weight significantly when using different solvent batches, for either catalyst. We discount the formation of a heterogeneous catalyst as the active species, as addition of excess $\mathrm{Hg}$ or sub-stoichiometric $\mathrm{PPh}_{3}$ ( 0.2 equivalents) once turnover was established did not act to significantly modify either cationic or neutral catalysts (Figure $6 \mathrm{~B}$ and $\mathrm{C}$ for catalyst 6 and 11, respectively). ${ }^{7 \mathrm{~b}, 51} \mathrm{H}_{2}$ release using $0.2 \mathrm{~mol} \% 6$ at $0.446 \mathrm{M} \mathrm{H}_{3} \mathrm{~B} \cdot \mathrm{NMeH}_{2}$ is fast (TOF $\sim 1700$ $\mathrm{hr}^{-1}$ ). This is considerably faster than for $\mathbf{1}$ (TOF $\sim 250 \mathrm{hr}^{-1}$ ),
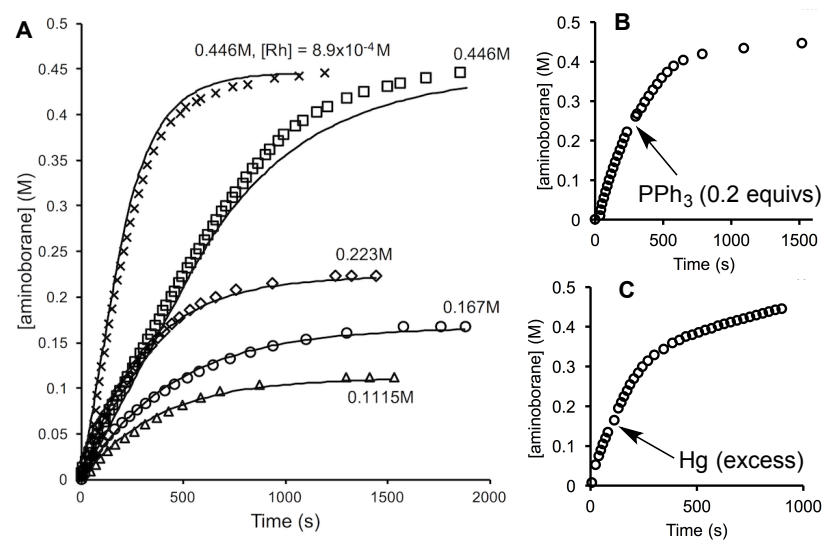

Figure 6. (A) Temporal data plots for polyaminoborane formation (as measured by $\mathrm{H}_{2}$ evolution) and simulated fits (lines) for catalyst $6\left(4.45 \times 10^{-4} \mathrm{M}\right.$ except where stated $)$ and $\mathrm{H}_{3} \mathrm{~B} \cdot \mathrm{NMeH}_{2}(\triangle=$ $0.1115 \mathrm{M}, \circ=0.167 \mathrm{M}, \diamond=0.223 \mathrm{M}$ and $\square=0.446 \mathrm{M}) . \times=6$ $\left(8.9 \times 10^{-4} \mathrm{M}\right), \mathrm{H}_{3} \mathrm{~B} \cdot \mathrm{NMeH}_{2}(0.446 \mathrm{M})$. The variable induction period of between 20 and 90 seconds has been removed from the data. (B) Effect of sub-stoichiometric $\mathrm{PPh}_{3}(0.2$ equiv.) added at $\mathrm{t}$ $=250 \mathrm{~s}:[6]=8.9 \times 10^{-4} \mathrm{M},\left[\mathrm{H}_{3} \mathrm{~B} \cdot \mathrm{NMeH}_{2}\right]=0.446 \mathrm{M}$. Note the induction period is shown. (C) Effect of excess $\mathrm{Hg}$ (1500 equiv.) at $\mathrm{t}=120 \mathrm{~s}:[\mathbf{1 1}]=8.9 \times 10^{-4} \mathrm{M},\left[\mathrm{H}_{3} \mathrm{~B} \cdot \mathrm{NMeH}_{2}\right]=0.446 \mathrm{M}$. but similar to $\mathbf{A}$ (TOF $\sim 2400 \mathrm{hr}^{-1}, 0.5 \mathrm{M} \mathrm{H}$ B $\cdot \mathrm{NMeH}_{2}, 0.1$ $\mathrm{mol} \%)^{4 a}$ and comparable with the fastest catalysts reported for $\mathrm{H}_{3} \mathrm{~B} \cdot \mathrm{NH}_{3}$ or $\mathrm{H}_{3} \mathrm{~B} \cdot \mathrm{NMe}_{2} \mathrm{H}$ dehydrocoupling. ${ }^{5 \mathrm{a}, 28,52}$

These data for catalyst $\mathbf{6}$ were simulated under a variety of scenarios. The temporal profile observed, especially at the highest concentration of $\mathrm{H}_{3} \mathrm{~B} \cdot \mathrm{NMeH}_{2}=0.446 \mathrm{M}$, suggests saturation kinetics are operating, i.e. initial zero-order in substrate, as we have modelled previously for the dehydrocoupling of amine-boranes using catalyst $1 .{ }^{5 \mathrm{~b}}$ However, the analysis of the data did not provide a convincing solution for quasiirreversible amine-borane coordination to the metal center. Instead a simple first-order model in substrate that took into account the limiting solubility of $\mathrm{H}_{3} \mathrm{~B} \cdot \mathrm{NMeH}_{2}$ in $1,2-\mathrm{F}_{2} \mathrm{C}_{6} \mathrm{H}_{4}$ solvent $(0.22 \mathrm{M})$, accounted best for all the observed data. Experimentally this is confirmed by a visual inspection of the catalysis reaction, and reflects the relatively poor solubility of $\mathrm{H}_{3} \mathrm{~B} \cdot \mathrm{NMeH}_{2}$ in $1,2-\mathrm{F}_{2} \mathrm{C}_{6} \mathrm{H}_{4}$. With this model in hand, overall second order rate constants were simulated (as shown in Figure 6A), for which an averaged $k=5.9 \pm 0.5 \mathrm{M}^{-1} \mathrm{~s}^{-1}$ was obtained. By using $\mathrm{D}_{3} \mathrm{~B} \cdot \mathrm{NMeH}_{2}$ at $0.1115 \mathrm{M}\left([\mathbf{6}]=2.23 \times 10^{-4}\right.$ $\mathrm{M})$, i.e. below the solubility limit, a KIE of $0.8 \pm 0.4$ for $\mathrm{BH} / \mathrm{BD}$ substitution is measured, while $\mathrm{H}_{3} \mathrm{~B} \cdot \mathrm{NMeD}_{2}$ results in a KIE of $4.6 \pm 0.2$ for $\mathrm{NH} / \mathrm{ND}$ substitution. The large KIE associated with ND suggests that $\mathrm{N}-\mathrm{H}$ cleavage is involved in the turnover limiting step. Similar KIEs have been reported for dehydrocoupling of $\mathrm{H}_{3} \mathrm{~B} \cdot \mathrm{NMe}_{2} \mathrm{H}$ using [ $\mathrm{TiCp}_{2}$ ] $(3.6 \pm 0.3)^{53}$ or $\mathrm{Rh}\left(\mathrm{PCy}_{3}\right)_{2}(\mathrm{H})_{2} \mathrm{Cl}(5.3 \pm 1.3)^{54}$ catalysts. For catalyst $\mathbf{1}$, in which a coordination/dehydrogenation/insertion mechanism is proposed, the KIE associated with $\mathrm{NH}$ activation in $\mathrm{H}_{3} \mathrm{~B} \cdot \mathrm{NMe}_{2} \mathrm{H}$ is smaller $(2.1 \pm 0.2){ }^{5 b}$ The small KIE associated with $\mathrm{B}-\mathrm{H}$ activation in the system here may indicate an equilibrium isotope effect that arises from reversible $\mathrm{B}-\mathrm{H}$ activation at the metal center, ${ }^{55}$ occurring prior to the turnover limiting step (Section 2.3), however within error it may also be close to unity, meaning that we are reluctant to over interpret this value. Although the two different KIE argue against a synchronous concerted $\mathrm{BH} / \mathrm{NH}$ activation, ${ }^{9 \mathrm{c}, 56}$ they could reflect a rather asynchronous transition state in which $\mathrm{BH}$ activation occurs much earlier than NH activation. ${ }^{17 \mathrm{~b}}$

The equivalent analysis of $\mathrm{H}_{2}$ release and resulting dehydrogenation kinetics for neutral catalyst $\mathbf{1 1}$ is additionally complicated by the fact that, due to the sensitivity of this catalyst, even repeat runs using the same batch of solvent differed significantly (initial rates varied by $25 \%$ at $0.446 \mathrm{M} \mathrm{H}_{3} \mathrm{~B} \cdot \mathrm{NMeH}_{2}$ and $0.2 \mathrm{~mol} \% \mathrm{11}$ ). We suggest that this is due to irreversible catalyst decomposition from trace impurities entrained in reaction vessels $\left(\mathrm{O}_{2}\right)$ even though substantial precautions for handling air-sensitive materials were taken. This means that detailed studies of catalyst loading or KIE experiments were not appropriate. Nevertheless all temporal plots of $\mathrm{H}_{2}$ release showed a similar profile to catalyst 6: essentially close to 1 equivalent of $\mathrm{H}_{2}$ formed and an initial psuedo zero order regime, although - interestingly - catalyst $\mathbf{1 1}$ does not display a measurable induction period. Simulating a representative example for catalyst 11 (TOF $\sim 1500 \mathrm{hr}^{-1}$ ) using the model developed for catalyst $\mathbf{6}$ gave a good fit and a second order rate constant $k=4.1 \mathrm{M}^{-1} \mathrm{~s}^{-1}$, similar to 6 .

Thus, even though both catalyst systems operate at a similar overall rate, likely by a similar chain-growth mechanism (Section 2.5), and are homogenous, they promote very different degrees of polymerization: with neutral catalyst $\mathbf{1 1}$ producing significantly longer polymer than 6 (Table 2 and Figure 5). 
2.7 Catalyst speciation during, and post, catalysis.

2.7.1 [Rh $\left.\left(\kappa^{3}-P, O, P-X a n t p h o s-{ }^{i} P r\right)(H)_{2}\left(\eta^{1}-H_{3} B \cdot N M e_{3}\right)\right]-$

$\left[\boldsymbol{B} A \boldsymbol{r}^{F}{ }_{4}\right]$, 6. As dehydropolymerization is performed at low catalyst loadings, directly interrogating reaction mixtures to determine the fate of the catalyst by NMR spectroscopic techniques is difficult. However, at the end of catalysis $(0.4 \mathrm{~mol} \%$, $6.6 \mathrm{mg} \mathrm{6}, 20 \mathrm{~min}$ ) concentration of the reaction mixture allowed for analysis by ${ }^{31} \mathrm{P}\left\{{ }^{1} \mathrm{H}\right\}$ NMR spectroscopy. Although a weak spectrum resulted, a doublet of doublets at $\delta 47.5[\mathrm{~J}=$ $174,6 \mathrm{~Hz}$ ] could be resolved. Repeating catalysis at $10 \mathrm{~mol} \%$ (e.g. $20 \mathrm{mg} \mathrm{6)}$ resulted in the same major organometallic complex (ca. 85\%), but now two minor components (ca. $15 \%$ combined) could also be observed. The major species was independently prepared by addition of $\left[\mathrm{NBu}_{4}\right]\left[\mathrm{BH}_{4}\right]$ to complex 6 (as its $\left[\mathrm{BAr}_{4}{ }^{\mathrm{Cl}}\right]^{-}$salt, ${ }^{57} \mathrm{Ar}^{\mathrm{Cl}}=3,5-\mathrm{Cl}_{2} \mathrm{C}_{6} \mathrm{H}_{3}$ ) which allowed for NMR data and a single-crystal X-ray structure to be obtained, although the single crystals were contaminated with $\left[\mathrm{NBu}_{4}\right]\left[\mathrm{BAr}_{4}^{\mathrm{Cl}}\right]$ as a co-product in the bulk. These data showed the structure to be $\left[\left\{\mathrm{Rh}\left(\kappa^{3}-\mathrm{P}, \mathrm{O}, \mathrm{P}-\mathrm{Xantphos}-{ }^{\mathrm{i}} \mathrm{Pr}\right)\right\}_{2} \mathrm{~B}\right]\left[\mathrm{BAr}{ }_{4}^{\mathrm{Cl}}\right]$, $14-\left[\mathrm{BAr}^{\mathrm{Cl}}{ }_{4}\right]$, Figure 7.
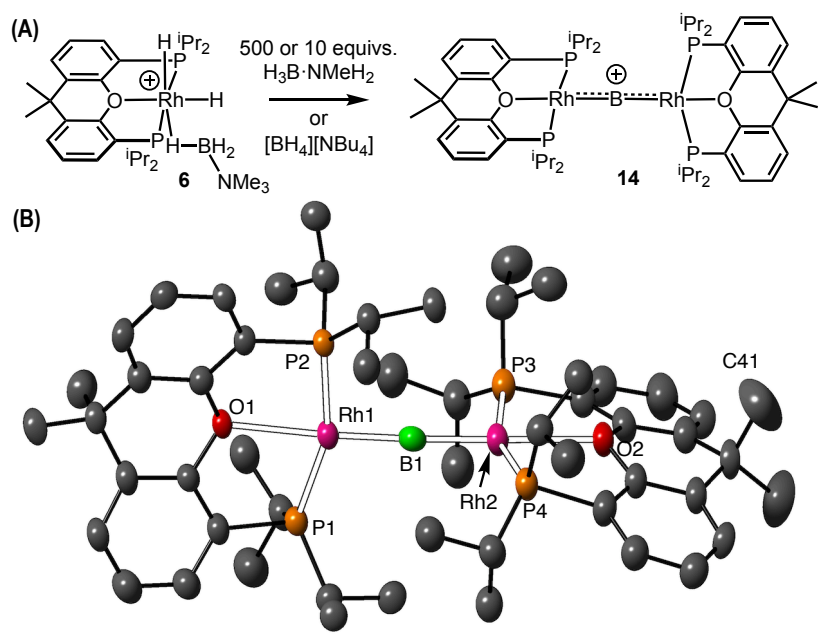

(C)

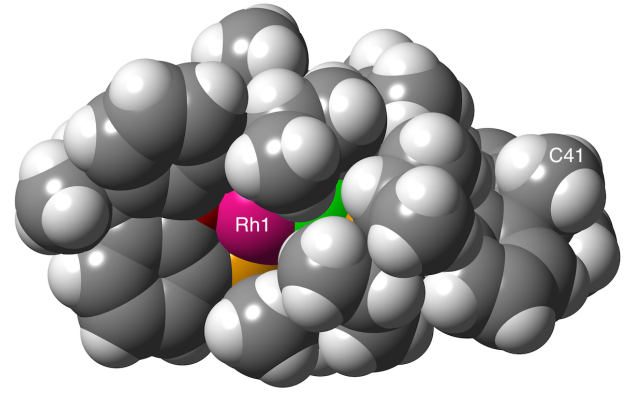

Figure 7. (A) Synthesis of complex 14-[BAr $\left.{ }_{4}{ }_{4}\right],\left[\mathrm{BAr}_{4}\right]^{-}$anion omitted. (B) Molecular structure of the cationic portion of $\mathbf{1 4}$ $\left[\mathbf{B A r}^{\mathrm{Cl}}{ }_{4}\right]$, displacement ellipsoids are shown at $50 \%$ probability level, $\mathrm{H}$-atoms and $\left[\mathrm{BAr}_{4}\right]^{-}$anion omitted. Selected bond distances $(\AA)$ and angles $\left({ }^{\circ}\right)$ : Rh1-B1, 1.880(8); Rh2-B1, 1.862(8); Rh1-O1, 2.343(2); Rh2-O2, 2.343(4); Rh1-B1-Rh2, 177.4(5); angle between $\mathrm{P} 1 / \mathrm{Rh} 1 / \mathrm{P} 2 / \mathrm{O} 1$ - P3/Ph2/P4/O2 90.2. (C) Space filling diagram (van der Waals radii).

Due to relatively poor crystal quality, and the reduction in high-angle data, the final refinement was of moderate quality $(R=7.9 \%)$, although the data collected proved adequate for confirming connectivity and bond metrics. Complex 14[BAr ${ }_{4}{ }_{4}$ ] has a $\mathrm{Rh}_{2}$ dimetallic unit that is spanned by a single $\mathrm{B}$ atom [Rh-B-Rh $177.4(5)^{\circ}$ ]. The Xantphos- $-{ }^{\mathrm{i}} \mathrm{Pr}$ ligands adopt a $m e r-\kappa^{3} \mathrm{P}, \mathrm{O}, \mathrm{P}$ geometry that places the central oxygen atom trans to the boron. As discussed later, the lack of high-field signals in the ${ }^{1} \mathrm{H}$ NMR spectrum, very low field chemical shift of the ${ }^{11} \mathrm{~B}$ resonance and mass-spectral data all indicate that there are no hydrides associated with the complex. The $\mathrm{Rh}-\mathrm{B}$ distances are both short [1.880(8) and 1.862(8) $\AA$ ], and comparable to closely related iron $^{58}$ and ruthenium ${ }^{59}$ dimetalloborylenes $\left[\left\{\left(\eta^{5}-\mathrm{C}_{5} \mathrm{H}_{4} \mathrm{R}\right)(\mathrm{CO})_{2} \mathrm{M}\right\}_{2} \mathrm{~B}\right]^{+}[\mathrm{M}=\mathrm{Fe}, \mathrm{R}=\mathrm{Me} ; \mathrm{M}=$ $\mathrm{Ru}, \mathrm{R}=\mathrm{H}$; e.g. $\mathrm{Ru}-\mathrm{B}$ 1.931(3)/1.963(3) $\AA$; $\mathrm{Ru}-\mathrm{B}-\mathrm{Ru}$ $\left.175.5(2)^{\circ}\right]$. The $\mathrm{Rh}-\mathrm{B}$ distances are shorter than that measured in $\mathrm{Rh}\left(\kappa^{3}-\mathrm{P}, \mathrm{O}, \mathrm{P}-\mathrm{X}\right.$ antphos $\left.-{ }^{\mathrm{i}} \mathrm{Pr}\right)(\mathrm{Bpin})$ [1.981(4) $\AA$; pin = pina$\mathrm{col}^{27 \mathrm{a}}$ which has a formal covalent $\mathrm{Rh}-\mathrm{B}$ single bond, are longer than those in monometallic complexes with $\mathrm{M}=\mathrm{B}$ bonds, e.g. $\mathrm{Ru}\left(\mathrm{PCy}_{3}\right)_{2}(=\mathrm{BMes}) \mathrm{HCl}[1.780(4) \AA$, Mes $=$ mesityl], ${ }^{60}$ but are similar to group 9 aminoborylenes, e.g. [mer$\left.\operatorname{Ir}\left(\mathrm{PMe}_{3}\right)_{3} \mathrm{HCl}\left(=\mathrm{BN}^{\mathrm{i}} \mathrm{Pr}_{2}\right)\right]\left[\mathrm{B}\left(\mathrm{C}_{6} \mathrm{~F}_{5}\right)_{4}\right] \quad[1.897(5) \AA]^{61}$ in which electronic unsaturation at boron can be attenuated by conjugation with the nitrogen lone pair. These comparisons suggest some partial double bond character to the Rh-B bonding in 14 . Although the presence of $\mathrm{d} \pi-\mathrm{p} \pi^{58}$ bonding between the $\mathrm{Rh}$ and B may also be suggested by the orientation of the Xantphos${ }^{\mathrm{i}} \mathrm{Pr}$ ligands (angle between $\mathrm{Rh} / \mathrm{P}_{2} / \mathrm{O}$ planes $=90.2^{\circ}$ ), the steric requirements of interdigitation of the ${ }^{\mathrm{i}} \mathrm{Pr}$ groups likely dominate this geometry (Figure 7C). ${ }^{62}$ The $\mathrm{Rh}-\mathrm{O}$ distances [2.343(4) $\AA$ ] are longer than those observed in 6 [2.192(3) $\AA]$ and $\mathrm{Rh}\left(\kappa^{3}-\mathrm{P}, \mathrm{O}, \mathrm{P}-\mathrm{Xantphos}-{ }^{\mathrm{i}} \mathrm{Pr}\right)(\mathrm{Bpin})^{27 \mathrm{a}}$ [2.268(2) $\AA$ ], suggesting that the boron atom exerts a significant trans influence.

The ${ }^{1} \mathrm{H}$ (and ${ }^{1} \mathrm{H}\left\{{ }^{11} \mathrm{~B}\right\}$ ) NMR spectra of $\mathbf{1 4}$ (for both anions) showed an absence of hydride signals (between $\delta 0$ and $\delta-$ $50)$, while in the ${ }^{11} \mathrm{~B}$ NMR spectrum a very broad resonance at $\delta 135$ is observed, which is in the region associated with complexes in which there is a significant $\mathrm{M} \cdots \mathrm{B}$ multiple bonding component, ${ }^{63}$ and is considerably downfield shifted from the regions associated with amine $-{ }^{64}$ or aminoboranes ${ }^{1 \mathrm{~b}}$ interacting with metal centers. Electrospray Ionization Mass Spectroscopy (ESI-MS) showed the dominant cationic species to be singly charged with an isotope pattern that matched very well with a formulation of $\left[\left\{\mathrm{Rh}\left(\kappa^{3}-\mathrm{P}, \mathrm{O}, \mathrm{P}-\mathrm{Xantphos}-{ }^{\mathrm{i}} \mathrm{Pr}\right)\right\}_{2} \mathrm{~B}\right]^{+}$ $(\mathrm{m} / \mathrm{z}=1101.36$, calculated 1101.33). The doublet of doublets observed in the ${ }^{31} \mathrm{P}\left\{{ }^{1} \mathrm{H}\right\}$ NMR spectrum can be rationalised by a one bond and a three bond ${ }^{103} \mathrm{Rh}-{ }^{31} \mathrm{P}$ coupling (i.e. an $\mathrm{A}_{2} \mathrm{XX}^{\prime} \mathrm{A}_{2}{ }_{2}$ system), the size of the former [174 Hz] being consistent with a $\mathrm{Rh}(\mathrm{I})$ center, while smaller couplings to distal $\mathrm{Rh}$-centers in dimeric systems have been noted before, as observed in $\mathbf{1 4} .^{65}$ Complex $\mathbf{1 4}$ is particularly sensitive in solution and undergoes decomposition to unidentified species.

Scheme 9. Representation of possible bonding schemes for complex 14. Xantphos- ${ }^{i}$ Pr truncated.

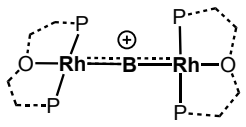

(a) dimetalloborylene

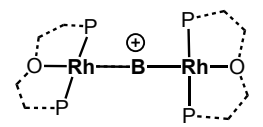

(b) borinium

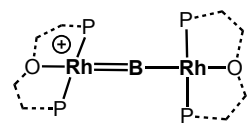

(c) dimetalloborido
Complex 14 can be described by three valence extremes (Scheme 9): (a) a dimetalloborylene in which a formally positively charged boron engages in both $\sigma-$ and $\pi$-bonding with two $\mathrm{Rh}(\mathrm{I})$ centers, (b) a cationic borinium with no multiple bonding and (c) a dimetalloboride with a $\mathrm{Rh}(\mathrm{III})=\mathrm{B}-\mathrm{Rh}(\mathrm{I})$ core. ${ }^{63}$ We discount (c) due to the symmetric $\mathrm{Rh}-\mathrm{B}-\mathrm{Rh}$ motif observed and NMR data that indicate equivalent $\mathrm{Rh}(\mathrm{I})$ centers, 
and have turned to DFT calculations to discriminate between (a) and (b). ${ }^{66}$

The optimized structure of complex 14 showed excellent agreement with the experimentally derived metrics with computed (average) Rh-B and Rh-O distances of $1.89 \AA$ and 2.37 $\AA$ respectively. An NBO calculation on $\mathbf{1 4}$ provides a Lewis structure in which the $\mathrm{B} 2 \mathrm{p}_{\mathrm{x}}$ and $2 \mathrm{p}_{\mathrm{y}}$ appear as lone vacant (LV) orbitals with significant initial populations of ca. 0.35 (the $\mathrm{z}$ direction being coincident with the Rh-B-Rh axis). Second order perturbation analysis indicates significant additional $\pi$-donation from $\mathrm{Rh}$ lone pair d-orbitals into both the $\mathrm{B} 2 \mathrm{p}_{\mathrm{x}}$ and $2 \mathrm{p}_{\mathrm{y}}\left(\Delta \mathrm{E}^{(2)}=15.1 \mathrm{kcal} \mathrm{mol}^{-1}\right.$ and $12.9 \mathrm{kcal} \mathrm{mol}^{-1}$ respectively). A degree of multiple bond character is also suggested by a computed Wiberg bond index of 1.11 while the computed NBO charge on B is +0.45 . QTAIM bond critical point (BCP) metrics associated with the Rh-B bond paths indicate a covalent interaction with a BCP electron density, $\rho(\mathrm{r})$ of $0.15 \mathrm{au}$, a negative values of the Laplacian, $\nabla^{2} \rho(\mathrm{r})=-0.15 \mathrm{au}$, and a total energy density, $H(\mathrm{r})$, of -0.11 au. These Rh-B BCPs also exhibit a low ellipticity $(\varepsilon=0.03)$ suggesting a near-spherical electron distribution at the BCP. Given the other computed evidence for a degree of multiple Rh-B bonding we interpret this result in terms of there being similar contributions to Rh-B $\pi$-bonding in both the $\mathrm{xz}$ and yz planes. This multiple bonding is most readily seen in the delocalised Kohn-Sham orbital HOMO-8 (Figure 8), and a similar, orthogonal contribution is also apparent in HOMO-5 (see Fig. S22). Taken together the body of computed evidence supports formulation (a) in Scheme 9 with species $\mathbf{1 4}$ best described as a dimetalloborylene.

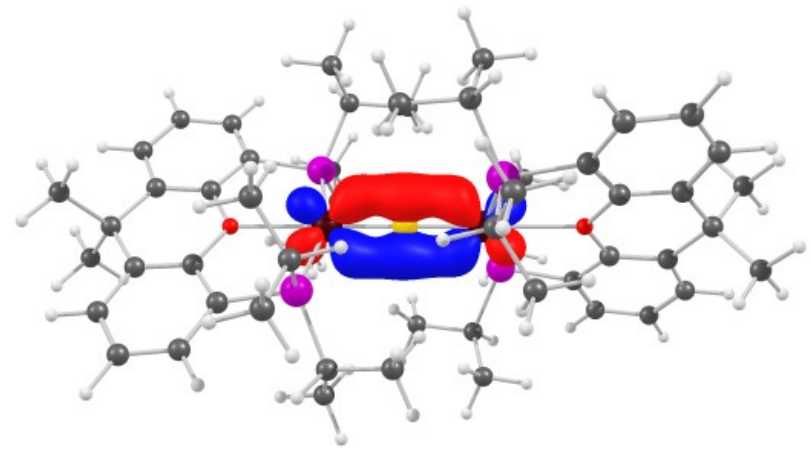

Figure 8. Kohn-Sham orbital (HOMO-8) exhibiting Rh-B $\pi$ bonding in 14

Having established that complex $\mathbf{1 4}$ is generated as the major organometallic species at the end of catalysis, its formation and onward reactivity was investigated as well as the identity of the other minor components observed. By following reaction progress in situ $(10 \mathrm{~mol} \%)$, the two minor components observed at the end of catalysis are shown to be initially dominant, and reduce in concentration over 20 minutes to afford 14 as the major species. These two new species were identified spectroscopically as $\left[\mathrm{Rh}\left(\kappa^{3}-\mathrm{P}, \mathrm{O}, \mathrm{P}-\mathrm{X}\right.\right.$ antphos$\left.\left.{ }^{\mathrm{i}} \mathrm{Pr}\right)(\mathrm{H})_{2}\left(\mathrm{H}_{3} \mathrm{~B} \cdot \mathrm{NMeH}_{2}\right)\right]\left[\mathrm{BAr}_{4}^{\mathrm{F}}\right], \mathbf{1 5}$, and the bridging borohydride complex $\quad\left[\left\{\mathrm{Rh}\left(\kappa^{3}-\mathrm{P}, \mathrm{O}, \mathrm{P}-\mathrm{Xantphos}-\right.\right.\right.$ $\left.\left.\left.{ }^{\mathrm{i}} \mathrm{Pr}\right)(\mathrm{H})_{2}\right\}_{2}\left(\mathrm{H}_{4} \mathrm{~B}\right)\right]\left[\mathrm{BAr}_{4}^{\mathrm{F}}\right]$, 16. Complex 15 can be independently synthesized from $7 / \mathrm{Na}\left[\mathrm{BAr}^{\mathrm{F}}{ }_{4}\right] / \mathrm{H}_{3} \mathrm{~B} \cdot \mathrm{NMeH}_{2}$ (Supporting Materials), and the NMR spectroscopic data are similar to, but distinct from, 6. $^{67}$ Complex $\mathbf{1 5}$ is relatively stable in solution, but addition of 10 equivalents of $\mathrm{H}_{3} \mathrm{~B} \cdot \mathrm{NMeH}_{2}$ results in the observation of $\mathbf{1 6}$ and ultimately 14. The promoting effect of additional amine--boranes towards dehydrocoupling has been noted previously. ${ }^{11 \mathrm{c}, 18 \mathrm{c}}$ For complex 16 a relative integral $2 \mathrm{H}$ resonance at $\delta-2.77$ is assigned to a bridging $\mathrm{BH}_{4}$ group that is undergoing rapid exchange between terminal $\mathrm{B}-\mathrm{H}$ and $\mathrm{B}-$ $\mathrm{H} \cdots \mathrm{Rh}$, while two relative integral $1 \mathrm{H}$ hydride resonance at $\delta$ -16.01 and $\delta-20.4$, that are mutually coupled, are assigned to terminal $\mathrm{Rh}-\mathrm{H}$. The ${ }^{31} \mathrm{P}\left\{{ }^{1} \mathrm{H}\right\}$ NMR spectrum shows an environment at $\delta 67.2[J(\mathrm{RhP})=111 \mathrm{~Hz}]$, indicating a $\mathrm{Rh}(\mathrm{III})$ center. In the ${ }^{11} \mathrm{~B}$ NMR spectrum a distinct, but broad, signal at $\delta$ -35.7 is observed, in the region associated with a borohydride ligand. The salient NMR data for $\mathbf{1 6}$ are similar to those reported for $\left[\left\{\left({ }^{\mathrm{i}} \mathrm{PrPNP}\right) \mathrm{FeH}(\mathrm{CO})\right\}_{2}\left(\mu^{2}, \eta^{1}: \eta^{1}-\mathrm{H}_{2} \mathrm{BH}_{2}\right)\right]\left[\mathrm{BPh}_{4}\right] .{ }^{65}$ Complex 16 can be directly synthesized by addition of 0.5 equivalents $\left[\mathrm{NBu}_{4}\right]\left[\mathrm{BH}_{4}\right]$ or $\sim 1$ equivalent of $\mathrm{BH}_{3} \cdot \mathrm{THF}$ to 6 . When prepared directly complex $\mathbf{1 6}$ evolves rapidly to give 14, so it is never observed in pure form. These observations suggest a reaction manifold $6 \rightarrow \mathbf{1 5} \rightarrow \mathbf{1 6} \rightarrow \mathbf{1 4}$ (Scheme 10).

Scheme 10. Formation of complexes 16 and 14. Xantphos${ }^{\mathrm{i}} \mathrm{Pr}$ ligand shown in truncated form. $\left[\mathrm{BAr}^{\mathrm{F}}{ }_{4}\right]^{-}$anions are not shown.
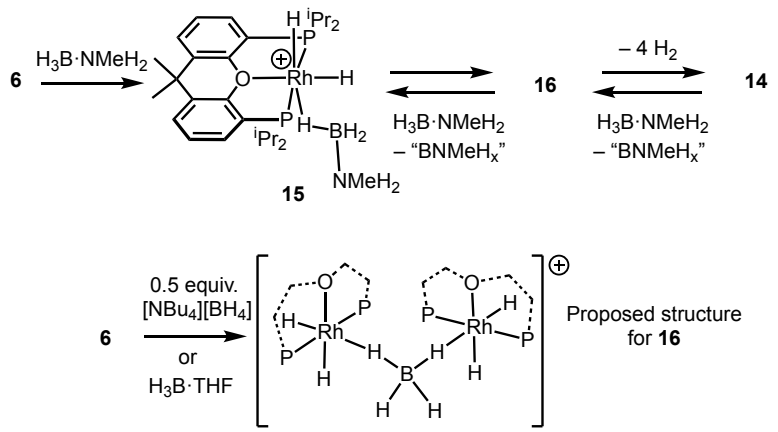

Guided by previous reports of hydride transfer at cationic metal centers ${ }^{2,68}$ and $\mathrm{B}-\mathrm{N}$ bond cleavage, ${ }^{4 \mathrm{f}, 9 \mathrm{c}, 54,69}$ we suggest a mechanism of formation of $\mathbf{1 6}$ from $\mathbf{6}$, under conditions of excess $\mathrm{H}_{3} \mathrm{~B} \cdot \mathrm{NMeH}_{2}$, Scheme 11. This involves coproduction of a boronium cation, $\left[\mathrm{BH}_{2}\left(\mathrm{NMeH}_{2}\right)(\mathrm{L})\right]^{+}\left(\mathrm{L}=\mathrm{NMeH}_{2}\right.$ or solvent), by attack of base-stabilized boryl by, e.g., $\mathrm{NMeH}_{2}$ (formed by $\mathrm{B}-\mathrm{N}$ bond cleavage). The resulting neutral $\mathrm{Rh}-$ hydride is trapped by $\mathrm{BH}_{3},{ }^{4 \mathrm{f}, 69 \mathrm{a}}$ and relatively fast addition of $\left[\mathrm{Rh}\left(\kappa^{3}-\mathrm{P}, \mathrm{O}, \mathrm{P}-\mathrm{X} \text { antphos }{ }^{-} \mathrm{i} \mathrm{Pr}\right)(\mathrm{H})_{2}\right]^{+}$forms $\mathbf{1 6}$. The formation of 16 from $6 / \mathrm{H}_{3} \mathrm{BH} \cdot \mathrm{THF}$ would follow a similar route. Consistent with boronium formation a triplet at $\delta-8.9[J=108 \mathrm{~Hz}]$ is observed in the ${ }^{11} \mathrm{~B}$ NMR spectrum (lit. $\delta-8.7$, br, $J \sim 90 \mathrm{~Hz}$, $\left.\left[\mathrm{BH}_{2}\left(\mathrm{NMeH}_{2}\right)_{2}\right]\left[\mathrm{SC}_{6} \mathrm{~F}_{5}\right]^{70}\right)$ when excess $\mathrm{H}_{3} \mathrm{~B} \cdot \mathrm{NMeH}_{2}$ is added to, in situ formed, $\mathbf{1 5}$. The subsequent formation of $\mathbf{1 4}$ from $\mathbf{1 6}$ involves the facile loss of 4 equivalents of $\mathrm{H}_{2}$, through a currently unresolved mechanism. Such an $\mathrm{H}_{2}$ loss is well established in metalloborane chemistry. ${ }^{11 b, 61,71}$

Scheme 11. Suggested mechanism for the formation of 16. Xantphos ligand and $\left[\mathrm{BAr}^{\mathrm{F}}{ }_{4}\right]^{-}$anions not shown.

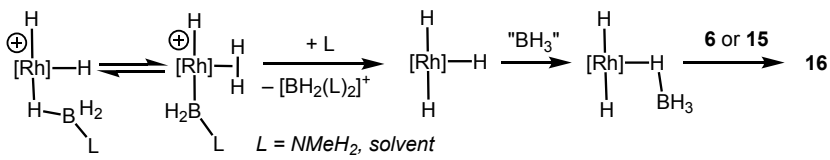

Complex 14 forms at the end of catalysis, and catalysis restarts on addition of more substrate (Section 2.5). Consistent with this, use of 14-[BAr $\left.{ }^{\mathrm{Cl}}{ }_{4}\right]$ as a catalyst $(0.2 \mathrm{~mol} \% \mathrm{Rh})$ afforded polymeric material $\left(M_{\mathrm{n}}=14,000 \mathrm{~g} \mathrm{~mol}^{-1}, \emptyset=2.7\right)$ similar to that starting from 6. Addition of 10 equivalents $\mathrm{H}_{3} \mathrm{~B} \cdot \mathrm{NMeH}_{2}$ 
to $14-\left[\mathrm{BAr}^{\mathrm{Cl}}{ }_{4}\right]$ showed the immediate generation of a mixture of 15 and 16, alongside $(\mathrm{HBNMe})_{3}$ and $\left[\mathrm{BH}_{2}\left(\mathrm{NMeH}_{2}\right)_{2}\right]^{+}$. Thus, although we cannot rule out that $\mathbf{1 4}$ is the actual catalyst, its temporal and reactivity profile suggest that it is more likely to play a dormant role in the catalytic cycle, with $\mathbf{1 5}$ or $\mathbf{1 6}$ observed as resting states.

2.7.2 Rh( $\left.\boldsymbol{\kappa}^{3}-\boldsymbol{P}, \boldsymbol{O}, \boldsymbol{P}-\mathrm{Xantphos}-^{i} \mathrm{Pr}\right) \mathrm{H}$ 11. Although complex 12 forms on time of mixing in $1,2-\mathrm{F}_{2} \mathrm{C}_{6} \mathrm{H}_{4}$ with $\mathbf{1 1}$, reaction with $\mathrm{H}_{3} \mathrm{~B} \cdot \mathrm{NMeH}_{2}$ ( 5 equiv.) showed the rapid formation of the tentatively assigned pentahydride complex $\mathrm{Rh}\left(\right.$ Xantphos $\left.{ }^{\mathrm{i}} \mathrm{Pr}\right) \mathrm{H}_{5}\left[\delta\left({ }^{31} \mathrm{P}\right) 87.3\right.$ (v br), 45.7 (v br), $\delta\left({ }^{1} \mathrm{H}\right)-$ 11.6 (v br), lit. ( $\mathrm{PhMe}-d_{8}$ ) ca. -13 (v br)], previously reported by Esteruelas by addition of $\mathrm{H}_{2}$ to $\mathbf{1 1},{ }^{28}$ and complete consumption of the amine-borane to form $\left(\mathrm{H}_{2} \mathrm{BNMeH}\right)_{\mathrm{n}}$, $(\mathrm{HBNMe})_{3}$ and $\left(\mathrm{H}_{2} \mathrm{BNMeH}\right)_{3}$. No $\left[\mathrm{BH}_{2}\left(\mathrm{NMeH}_{2}\right)_{2}\right]^{+}$was observed. At the end of catalysis these hydride-containing species remain active for dehydropolymerization $\left(M_{\mathrm{n}}=26,000 \mathrm{~g}\right.$ $\left.\mathrm{mol}^{-1}, Ð=2.3\right)$.

\subsubsection{IRh $\left(\kappa^{3}-P, O, P-X a n t p h o s-E t\right)(H)_{2}\left(\eta^{1-}\right.$}

$\left.\left.\mathrm{H}_{3} \mathrm{~B} \cdot \mathrm{NMe}_{3}\right)\right]\left[\mathrm{BAr}_{4}{ }_{4}\right], \mathbf{5}$. Complex 5 is a very poor catalyst for dehydropolymerization (Section 2.4). Addition of 2 equivalents of $\mathrm{H}_{3} \mathrm{~B} \cdot \mathrm{NMeH}_{2}$ to $\mathbf{5}$ showed the formation of a new species assigned using NMR spectroscopy and ESI-MS as the mono-cationic bridged aminoborane complex $\left[\left\{\mathrm{Rh}\left(\kappa^{3}-\mathrm{P}, \mathrm{O}, \mathrm{P}-\right.\right.\right.$ Xantphos-Et) $\left.\}_{2}(\mu-\mathrm{H})\left(\mu-\mathrm{H}_{2} \mathrm{BNMeH}\right)\right]\left[\mathrm{BAr}_{4}^{\mathrm{F}}\right] \quad 17$ (Scheme 12). Complex 17 becomes the dominant species in solution after 30 minutes, accompanied by 5 in a 7:3 ratio, and was identified by comparison with NMR data of related complexes $\left[\left\{\mathrm{Rh}\left({ }^{\mathrm{i}} \mathrm{Pr}_{2} \mathrm{P}\left(\mathrm{CH}_{2}\right)_{3} \mathrm{P}^{\mathrm{i}} \mathrm{Pr}_{2}\right)\right\}_{2}(\mu-\mathrm{H})\left(\mu-\mathrm{H}_{2} \mathrm{BNH}_{2}\right)\right]\left[\mathrm{BAr}_{4}{ }_{4}\right]^{5 \mathrm{~d}}$ and $\left[\left\{\mathrm{Rh}\left(\mu-\mathrm{Cy}_{2} \mathrm{PCH}_{2} \mathrm{PCy}_{2}\right) \mathrm{H}_{2}(\mu-\mathrm{H})\left(\mu-\mathrm{BNMe}_{2}\right)\right]\left[\mathrm{Al}\left\{\mathrm{OC}\left(\mathrm{CF}_{3}\right)_{3}\right\}\right.\right.$ 4]. ${ }^{50 \mathrm{a}}$ In particular the ${ }^{11} \mathrm{~B}$ NMR spectrum contains a broad signal at $\delta 61.1$, while in the ${ }^{1} \mathrm{H}$ NMR spectrum three broad hydride resonances at $\delta-5.82(1 \mathrm{H}, \mathrm{RhHB}),-9.41(1 \mathrm{H}$, RhHB), -11.16 (1 H, RhHRh) are observed, assigned on the basis of ${ }^{1} \mathrm{H}\left\{{ }^{11} \mathrm{~B}\right\} /{ }^{1} \mathrm{H}\left\{{ }^{31} \mathrm{P}\right\}$ decoupling experiments. The mechanism for formation of dimers such as $\mathbf{1 7}$ has been established, and pivots around hydride transfer from a B-H activated amine-borane to form a boronium cation, e.g. $\left[\mathrm{BH}_{2}\left(\mathrm{NMeH}_{2}\right)(\mathrm{L})\right]^{+}\left(\mathrm{L}=\mathrm{NMeH}_{2}\right.$ or solvent $)$, and a transient dimeric neutral hydride. ${ }^{5 \mathrm{~d}, 22,68}$ Protonation of this dimer by half an equivalent of the boronium leads to the observed product and loss of $\mathrm{H}_{2}$. Consistent with this mechanism, a short lived complex assigned to $\left[\mathrm{Rh}\left(\kappa^{3}-\mathrm{P}, \mathrm{O}, \mathrm{P}-\mathrm{X}\right.\right.$ antphos-Et $)(\mathrm{H})_{2}\left(\eta^{1}\right.$ $\left.\left.\mathrm{H}_{3} \mathrm{BNMeH}_{2}\right)\right]\left[\mathrm{BAr}_{4}^{\mathrm{F}}\right]$ is observed at the early stages of the reaction by ${ }^{1} \mathrm{H}$ and ${ }^{31} \mathrm{P}\left\{{ }^{1} \mathrm{H}\right\}$ NMR spectroscopy. These observations further underscore that initial hydride transfer at a cationic coordinated amine-borane complex is occurring. The formation of $\mathbf{1 7}$ is, presumably, driven by the ability for

Scheme 12. Formation of dimeric complex 17. [BAr $\left.{ }_{4}\right]^{-}$ anions are omitted for clarity. $L=$ solvent or $\mathrm{NMeH}_{2}$.

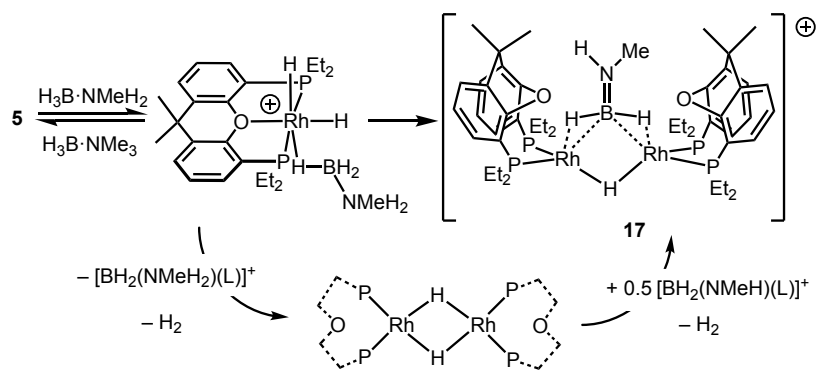

Xantphos-Et to adopt a $c i s-\kappa^{2}-\mathrm{P}, \mathrm{P}$ geometry on a Rh(I) center.

We have not been able to isolate complex $\mathbf{1 7}$ in pure form. When synthesized in situ and used in catalysis $(0.2 \mathrm{~mol} \% \mathrm{Rh}$, $\left.0.446 \mathrm{M}\left[\mathrm{H}_{3} \mathrm{~B} \cdot \mathrm{NMeH}_{2}\right]\right) \mathrm{H}_{2}$ evolution is very slow, with a TOF of $0.01 \mathrm{~s}^{-1}$, very similar to the rate observed for 5 (TOF $=$ $0.01 \mathrm{~s}^{-1}$ ), consistent with its rapid formation under catalytic conditions from $\mathbf{5}$.

The precise role of dimeric or monomeric $\{\mathrm{Rh}(\text { diphosphine })\}^{+}$ fragments in dehydropolymerization remains to be resolved, as both are implicated in catalysis. ${ }^{5 c, d}$ However, the isolation of 17, and its lack of reactivity, provides evidence to suggest that such dimeric hydride-bridged species are not catalysts in these particular Xantphos-alkyl systems - although their ability to act as off-cycle reservoirs for actual catalysts cannot be discounted. $^{72}$ The formation of dimeric species with $c i s-\kappa^{2}-\mathrm{P}, \mathrm{P}$ geometries with Xantphos-Et but not for Xantphos- ${ }^{\mathrm{i}} \mathrm{Pr}$ or Xantphos- ${ }^{t} \mathrm{Bu}$ again suggests steric effects are important in determining the course of reaction.

2.7.4 ${ }^{\mathrm{t}} \mathrm{Bu}$ systems - neutral and cationic. [Rh( $\kappa^{3}-\mathbf{P}, \mathbf{O}, \mathbf{P}$ Xantphos- $\left.\left.{ }^{t} \mathbf{B u}\right)(\mathbf{H})_{2}\right]\left[\mathbf{B A r}^{\mathrm{F}}{ }_{4}\right], \mathbf{1 0}$. Although $\mathbf{1 0}$ does not form a complex with $\mathrm{H}_{3} \mathrm{~B} \cdot \mathrm{NMe}_{3}$, it does promote $\mathrm{H} / \mathrm{D}$ exchange (Section 2.3) and it was found to be capable of $\mathrm{BH} / \mathrm{NH}$ activation of $\mathrm{H}_{3} \mathrm{~B} \cdot \mathrm{NMeH}_{2}$ to afford polymeric $\left(\mathrm{H}_{2} \mathrm{BNMeH}\right)_{\mathrm{n}}$, albeit more slowly, in lower yield and with more side reactions than the ${ }^{\mathrm{i}} \mathrm{Pr}$ analogue 6 (Table 1). Catalysis carried out at $10 \mathrm{~mol} \%$ to determine the fate of the catalyst produced predominantly $(\mathrm{HBNMe})_{3}$, alongside a small quantity of $\left(\mathrm{H}_{2} \mathrm{BNMeH}\right)_{\mathrm{n}}$ and a number of other side products. ${ }^{1} \mathrm{H}$ and ${ }^{31} \mathrm{P}\left\{{ }^{1} \mathrm{H}\right\}$ NMR spectroscopy indicated that $\mathbf{1 0}$ was the only organometallic species in solution at the end of catalysis. Interestingly, under these conditions a small amount of $\left[\mathrm{BH}_{2}\left(\mathrm{NMeH}_{2}\right)_{2}\right]^{+}$was also observed, suggesting hydride transfer processes are occurring. Addition of one equivalent of $\mathrm{H}_{3} \mathrm{~B} \cdot \mathrm{NMeH}_{2}$ to $\mathbf{1 0}$ did not form a $\sigma-$ $\mathrm{H}_{3} \mathrm{~B} \cdot \mathrm{NMeH}_{2}$ complex [Rh $\left(\kappa^{3}-\mathrm{P}, \mathrm{O}, \mathrm{P}-\mathrm{X}\right.$ antphos $\left.-{ }^{\mathrm{t}} \mathrm{Bu}\right)(\mathrm{H})_{2}\left(\eta^{1}-\right.$ $\left.\left.\mathrm{H}_{3} \mathrm{~B} \cdot \mathrm{NMeH}_{2}\right)\right]-\left[\mathrm{BAr}_{4}^{\mathrm{F}}\right.$ ], such as $\mathbf{1 5}$, indicating that the bulky ${ }^{\mathrm{t}} \mathrm{Bu}$ group inhibits $\mathrm{H}_{3} \mathrm{~B} \cdot \mathrm{NMeH}_{2}$ from binding strongly. That steric variations of the Xantphos-R ligand have significant differences in reactivity has parallels to related pincer complexes, such as $\operatorname{Ir}(\mathrm{R}-\mathrm{POCOP})(\mathrm{H})_{2} \mathrm{R}={ }^{\mathrm{i}} \mathrm{Pr}$ and ${ }^{\mathrm{t}} \mathrm{Bu} .{ }^{73}$

$\mathbf{R h}\left(\boldsymbol{\kappa}^{\mathbf{3}}-\mathbf{P}, \mathbf{O}, \mathbf{P}-\mathbf{X}\right.$ antphos- $\left.{ }^{\mathbf{t}} \mathbf{B u}\right) \mathbf{H}, \mathbf{1 3}$. Complex $\mathbf{1 3}$ is observed as the sole organometallic species during catalysis $(1 \mathrm{~mol} \%)$, indicating that it is the likely resting state in this system. As for 10 , the ${ }^{t} \mathrm{Bu}$ groups promote slower and less-selective dehydropolymerization.

\subsection{Comments on the Mechanism}

Use of a number of closely related rhodium-based Xantphosalkyl systems, in which sterics, charge and number of hydride ligands on the precatalyst are varied, has allowed for insight into the mechanism of $\mathrm{H}_{3} \mathrm{~B} \cdot \mathrm{NMeH}_{2}$ dehydropolymerization. The studies provide the following observations:

1) The essential chain-growth characteristics of polymerization suggests a mechanism that involves rapid addition of a reactive monomer (i.e. $\mathrm{H}_{2} \mathrm{~B}=\mathrm{NMeH}$ ) to a growing polymer chain.

2) The catalyst remains active and is not irreversibly consumed in the polymerization process, as shown by recharging experiments.

3) The absence of a strong effect of catalyst loading on degree of polymerization, and lack of control of polymerization using 
$\mathrm{H}_{2}$, suggests a coordination/insertion chain growth mechanism is likely not operating.

4) Although complicated by solubility effects, dehydrogenation is first order in $\mathrm{H}_{3} \mathrm{~B} \cdot \mathrm{NMeH}_{2}$ for both cationic 6 and neutral 11, with broadly similar rate constants. Despite this there is a dramatic difference in the degree of polymerization observed: neutral 11 produces polymer that is considerably longer than that from cationic $\mathbf{6}$.

5) That different speciation is observed between cationic $(\mathrm{Rh}(\mathrm{III}))$ and neutral $(\mathrm{Rh}(\mathrm{I}))$ systems suggests that the two systems do not resolve into a common catalyst.

6) Speciation studies all point to hydride-containing species being pervasive; and hydride transfer processes in the cationic system occurring with the concomitant formation of boronium cations.

These data, however, do not allow us to definitively resolve the structure of the active catalyst. Nevertheless, based on the above speciation data we propose that neutral hydride species are involved. For the cationic system a plausible mechanistic scheme is shown in Scheme 13A. Coordination of $\mathrm{H}_{3} \mathrm{~B} \cdot \mathrm{NMeH}_{2}$ and subsequent reversible $\mathrm{B}-\mathrm{H}$ activation forms boryl/hydride II. Pathway A proceeds through intramolecular $\mathrm{NH}$ activation, via transition state $\mathbf{V},{ }^{28,56 \mathrm{~b}}$ in which rate determining $\mathrm{N}-\mathrm{H}$ transfer occurs to a cationic $\mathrm{Rh}-$ hydride, with the formation of the reactive monomer $\mathrm{H}_{2} \mathrm{~B}=\mathrm{NMeH}$. Alternatively intermediate II can evolve via boronium formation to give neutral hydride III, ${ }^{74}$ pathway B. Subsequent, rate determining, intermolecular protonation by $\left[\mathrm{BH}_{2}\left(\mathrm{NMeH}_{2}\right)_{2}\right]^{+}$reforms cationic dihydride IV. This is similar to the mechanism proposed by Conejero for $\mathrm{H}_{3} \mathrm{~B} \cdot \mathrm{NMe}_{2} \mathrm{H}$ dehydrocoupling using cationic Pt-based catalysts. ${ }^{22,75}$ Complex $\mathbf{1 4}$ forms in an offcycle process by reaction of $\mathrm{BH}_{3} / \mathbf{I V}$ with III (Pathway $\mathbf{C}$ ). For Xantphos- ${ }^{i}$ Pr resting states of $\mathbf{I}$ (i.e. 6) and $\mathbf{1 6}$ are observed, with bulker Xantphos- ${ }^{\mathrm{t}} \mathrm{Bu}$ it is IV (i.e. 10), and with less bulky Xantphos-Et dimeric $\mathbf{1 7}$ forms rapidly. Boronium $\left[\mathrm{BH}_{2}\left(\mathrm{NMeH}_{2}\right)_{2}\right]^{+}$thus potentially plays two different roles: as a co-intermediate (pathway B) or as a side-product bifurcating from pathway A that eventually forms dormant species $\mathbf{1 4}$ (pathway C).
To probe this, polymerization was repeated at $0.1115 \mathrm{M}$ $\mathrm{H}_{3} \mathrm{~B} \cdot \mathrm{NMeH}_{2}, 0.2 \mathrm{~mol} \% \mathbf{6}$, with and without the addition of excess, independently synthesized, $\left[\mathrm{BH}_{2}\left(\mathrm{NMeH}_{2}\right)_{2}\right]\left[\mathrm{BAr}_{4}^{\mathrm{F}}\right](2$ mol\%). Figure 9 details the temporal evolution plots obtained, alongside the first order rate plots for these data. Post induction period, during the first-order region of catalysis, a $\sim 3$ fold increase in $k_{\text {obs }}$ was observed with added boronium. This is consistent with proposed mechanistic pathway $\mathbf{B}$, which intimately involves $\left[\mathrm{BH}_{2}\left(\mathrm{NMeH}_{2}\right)_{2}\right]^{+}$, however we cannot discount that pathway $\mathbf{A}$ is also operating under these conditions. Polymer produced under the conditions of excess boronium was of low molecular weight, but characteristic of catalyst 6 $\left(M_{\mathrm{n}}=6,000 \mathrm{~g} \mathrm{~mol}^{-1}, D=1.7\right) .^{76}$

We suggest that neutral $\mathbf{1 1}$ and $\mathbf{1 3}$ operate in a similar manner to that proposed by Esteruelas for dehydrogenation of $\mathrm{H}_{3} \mathrm{~B} \cdot \mathrm{NH}_{3}$, for which calculations indicate that $\mathrm{B}-\mathrm{H}$ bond cleavage is followed by an (albeit high energy) $\mathrm{N}-\mathrm{H}$ activation and elimination of $\mathrm{H}_{2} \mathrm{~B}=\mathrm{NH}_{2}$, operating via a $\mathrm{N}-\mathrm{H} \cdots \mathrm{H}-\mathrm{Rh}$ dihydrogen interaction, VII. ${ }^{28}$ The Xantphos- ${ }^{\mathrm{i}} \mathrm{Pr}$ is proposed to change from $m e r-\kappa^{3}-\mathrm{P}, \mathrm{O}, \mathrm{P}$ to $c i s-\kappa^{2}-\mathrm{P}, \mathrm{P}$ in this cycle.

A fast chain-growth mechanism for polymerization, but not coordination/insertion, is indicated by the dehydropolymerization kinetics. We thus suggest a chain propagation process in which a low concentration of a separate, likely neutral, rhodium hydride initiator/catalyst forms a Lewis-base/acid adduct with $\mathrm{H}_{2} \mathrm{~B}=\mathrm{NMeH}$ which thus develops a lone pair on the nitrogen (i.e. an aminoborohydride). ${ }^{77}$ Subsequent, fast, headto-tail end-chain ${ }^{13 \mathrm{~b}} \mathrm{~B}-\mathrm{N}$ bond forming events lead to polyaminoborane (Scheme 13B). Support for this mechanism comes from Manners' experimental ${ }^{4 a}$ and Paul's computation$\mathrm{al}^{24}$ studies on the $\operatorname{Ir}(\mathrm{POCOP})(\mathrm{H})_{2}$ catalyst system, $\mathbf{A}$, the latter demonstrating a very low energy pathway $\left(\sim 7 \mathrm{kcal} \mathrm{mol}^{-1}\right)$ for this $\mathrm{B}-\mathrm{N}$ bond forming process, Scheme 14A. Given the similarities between $\kappa^{3}-\mathrm{P}, \mathrm{O}, \mathrm{P}-\mathrm{X}$ antphos ligands and POCOP-type pincer ligands it is not unreasonable to suggest a similar mechanism is operating here. This proposed end-chaingrowth mechanism also has parallels with that suggested by Baker

Scheme 13. Suggested mechanism for dehydropolymerization. Xantphos ligands and $\left[\mathrm{BAr}_{4}^{\mathrm{F}}\right]^{-}$anions not shown.

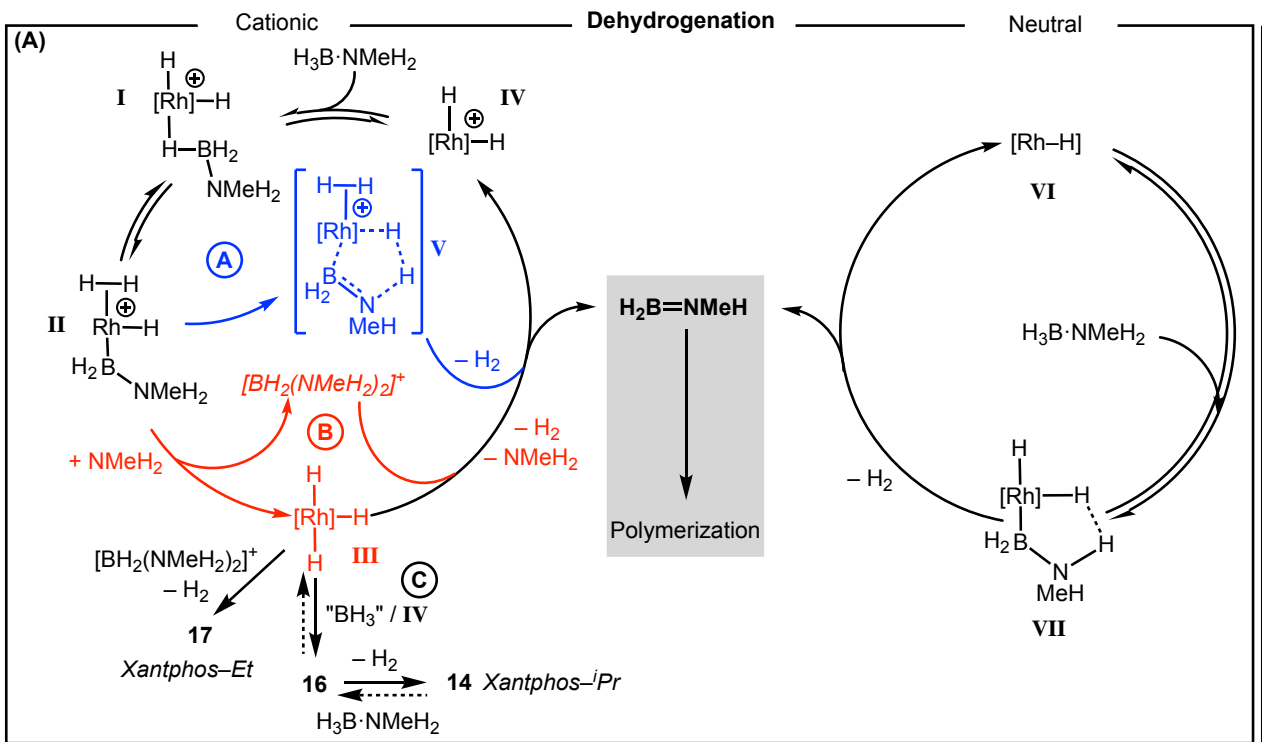



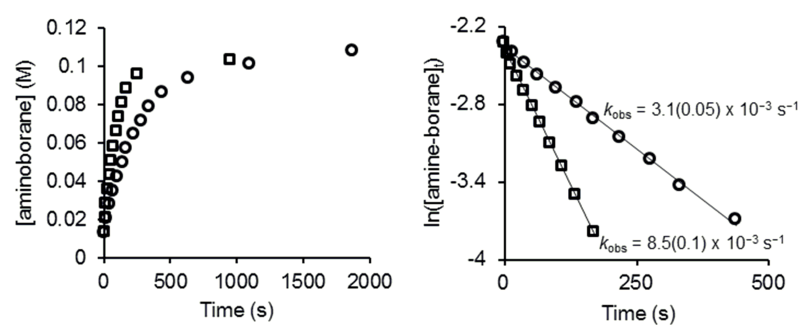

Figure 9. Left: Temporal data plots for polyaminoborane formation (as measured by $\mathrm{H}_{2}$ evolution) for catalyst $6\left(2.23 \times 10^{-4}\right.$ M) and $\mathrm{H}_{3} \mathrm{~B} \cdot \mathrm{NMeH}_{2} \quad(0.1115 \quad \mathrm{M}) \quad(\mathrm{O}=$ without $\left[\mathrm{BH}_{2}\left(\mathrm{NMeH}_{2}\right)_{2}\right]\left[\mathrm{BAr}_{4}^{\mathrm{F}}\right], \quad \square=2.23 \times 10^{-3} \mathrm{M}$ $\left.\left[\mathrm{BH}_{2}\left(\mathrm{NMeH}_{2}\right)_{2}\right]\left[\mathrm{BAr}_{4}^{\mathrm{F}}\right]\right)$. Induction periods not shown. Right: First order rate plots showing calculated $k_{\text {obs }}$.

for dehydropolymerization of $\mathrm{H}_{3} \mathrm{~B} \cdot \mathrm{NH}_{3}$ using $\mathrm{Fe}\left(\mathrm{PhNCH}_{2} \mathrm{CH}_{2} \mathrm{NPh}\right)\left(\mathrm{Cy}_{2} \mathrm{PCH}_{2} \mathrm{CH}_{2} \mathrm{PCy}_{2}\right),{ }^{4 \mathrm{c}}$ and captures aspects of the mechanism suggested by Schneider in which the catalyst system acts in a "bifunctional" manner to dehydrogenate $\mathrm{H}_{3} \mathrm{~B} \cdot \mathrm{NH}_{3}$ and also promote polymerization. ${ }^{4 \mathrm{e}, \mathrm{f}}$ It is also related to Sneddon's base-promoted anionic, ${ }^{37}$ and Aldridge's Frustrated-Lewis-Pair (Scheme 14B), ${ }^{12 \mathrm{c}}$ chain-growth dehydrooligomerizations.

We cannot discount a process in which polymerization occurs off-metal. Arguing against this, the different molecular weights of polymer produced with different catalysts, even though dehydrogenation $\left(\mathrm{H}_{2}\right.$ evolution) runs at similar rates, suggest metal involvement in the propagation step. We argue against low concentrations of $\left[\mathrm{H}_{2} \mathrm{~B}\left(\mathrm{NMeH}_{2}\right)_{2}\right]^{+}$being an initiating species ${ }^{78}$ as we have previously demonstrated that closely related boronium salts do not promote dehydrocoupling at 0.5 mol\% loading. ${ }^{5 \mathrm{~d}}$

Scheme 14. (A) Paul's proposed polymerization mechanism; (B) FLP end-chain B-N formation.
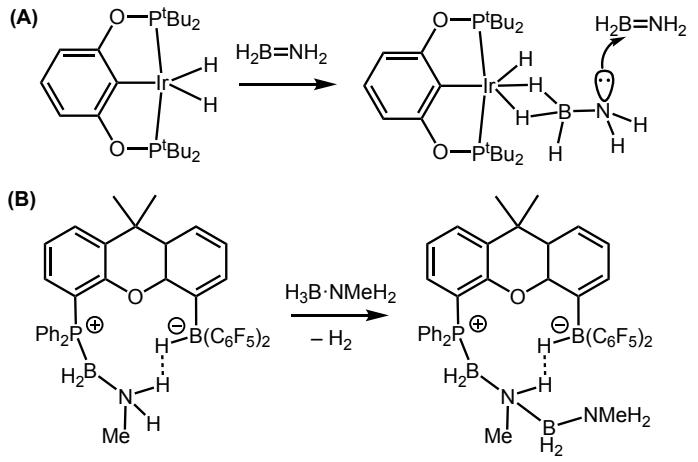

In chain-growth processes the interrelation of rates of initiation, termination and propagation are very system dependent. ${ }^{45}$ Adding to this potential complexity, termination events in amine-borane dehydropolymerization are currently opaque to experiment. ${ }^{24}$ It is likely that that subtle changes in dehydrogenation rate, the relative ratio of initiator sites for polymerization and termination events (promoted by the sterics and electronics of the metal-ligand fragment and/or products of B$\mathrm{N}$ bond cleavage) all combine to control the efficiency and degree of dehydopolymerization. It is, however, clear is that when considering the Xantphos- ${ }^{i} \mathrm{Pr}$ systems, the neutral precatalyst promotes higher degrees of polymerization, but precisely which of the above factors governs this still remains to be resolved.

\section{Conclusions}

The studies described here show that changes in the sterics and overall charge can have a significant effect on the course of $\mathrm{H}_{3} \mathrm{~B} \cdot \mathrm{NMeH}_{2}$ dehydropolymerization when using $\{\mathrm{Rh}($ Xantphos-R) $\}$-based catalysts. With Xantphos-Et the more flexible ligand allows the catalyst to access dimeric essentially inactive - species; while the bulkier and less flexible Xantphos- ${ }^{t} \mathrm{Bu}$ ligand leads to lower selectivites for polyaminoborane production and considerably slower turnovers. The optimal position comes with Xantphos- ${ }^{i} \mathrm{Pr}$, for which fast turnovers and good selectivities result. Speciation studies point towards neutral, hydride containing, active catalysts, indicated to be formed from the cationic precatalysts by hydride transfer routes from the borane. It is interesting to note that for closely related alkane dehydrogenation catalysts based upon $\operatorname{Ir}($ pincer- $\mathrm{R})(\mathrm{H})_{2}$ motifs ${ }^{\mathrm{i}} \mathrm{Pr}$-functionalized ligands often also show improved performance over ${ }^{\mathrm{t}} \mathrm{Bu}{ }^{79}$

The development of such structure/activity relationships, a methodology so heavily exploited in olefin polymerization, ${ }^{14}$ is central to harnessing metal-catalyzed dehydropolymerization for the production of polyaminoboranes "to order". As well as resolving the fundamental details of this complex and nuanced catalytic system, future studies also need to consider more practical elements such as the development of catalysts that do not become entrained in the resulting polymer and a better understanding and control of the stereochemical aspects of these potentially exciting new materials.

\section{ASSOCIATED CONTENT}

\section{Supporting Information}

The Supporting Information is available free of charge on the ACS Publications website at DOI: $x x x x$

Experimental and characterization details, including NMR spectroscopic data, and X-ray crystallographic data, and computational details (PDF)

\section{AUTHOR INFORMATION}

\section{Corresponding Author \\ * andrew.weller@chem.ox.ac.uk.}

\section{Author Contributions}

The manuscript was written through contributions of all authors. $\$$ These authors contributed equally.

\section{ACKNOWLEDGMENT}

The EPSRC for funding (EP/M024210/1). The research leading to these results has received funding from the European Research Council under the European Union's Seventh Framework Programme (FP7/2007-2013) / ERC grant agreement $n^{\circ}$ [340163]. Joshua I. Levy is thanked for developing the GPC modelling software. Professors George Britovsek (Imperial College) and Ian Manners (University of Bristol) for helpful discussions.

\section{REFERENCES}

(1) (a) Staubitz, A.; Robertson, A. P. M.; Sloan, M. E.; Manners, I. Chem. Rev. 2010, 110, 4023;(b) Leitao, E. M.; Jurca, T.; Manners, I. Nat. Chem. 2013, 5, 817;(c) Johnson, H. C.; Hooper, T. N.; Weller, A. S. Top. Organomet. Chem. 2015, 49, 153;(d) Bhunya, S.; Malakar, T.; Ganguly, G.; Paul, A. ACS Catal. 2016, 6, 7907;(e) Pons, V.; Baker, R. T.; Szymczak, N. K.; Heldebrant, D. J.; Linehan, J. C.; Matus, M. H.; Grant, D. J.; Dixon, D. A. Chem. Commun. 2008, 6597;(f) Priegert, A. M.; Rawe, B. W.; Serin, S. C.; Gates, D. P. Chem. Soc. Rev. 2016, 45, 922. 
(2) (a) Bernard, S.; Miele, P. Materials 2014, 7, 7436;(b) Du, V.; Whittell, G.; Manners, I. Dalton Trans. 2016, 45, 1055;(c) Wang, X.; Hooper, T. N.; Kumar, A.; Priest, I. K.; Sheng, Y.; Samuels, T. O. M.; Wang, S.; Robertson, A. W.; Pacios, M.; Bhaskaran, H.; Weller, A. S.; Warner, J. H. CrystEngComm 2017, 19, 285;(d) Staubitz, A.; Presa Soto, A.; Manners, I. Angew. Chem. Int. Ed. 2008, 47, 6212.

(3) (a) Rossin, A.; Peruzzini, M. Chem. Rev. 2016, 116, 8848;(b) Dietrich, B. L.; Goldberg, K. I.; Heinekey, D. M.; Autrey, T.; Linehan, J. C. Inorg. Chem. 2008, 47, 8583.

(4) (a) Staubitz, A.; Sloan, M. E.; Robertson, A. P. M.; Friedrich, A.; Schneider, S.; Gates, P. J.; Schmedt auf der Günne, J.; Manners, I. J. Am. Chem. Soc. 2010, 132, 13332;(b) Vance, J. R.; Robertson, A. P. M.; Lee, K.; Manners, I. Chem. Eur. J. 2011, 17, 4099;(c) Baker, R. T.; Gordon, J. C.; Hamilton, C. W.; Henson, N. J.; Lin, P.-H.; Maguire, S.; Murugesu, M.; Scott, B. L.; Smythe, N. C. J. Am. Chem. Soc. 2012, 134, 5598;(d) Esteruelas, M. A.; Olivan, M.; Vélez, A. Inorg. Chem. 2013, 52, 5339;(e) Marziale, A. N.; Friedrich, A.; Klopsch, I.; Drees, M.; Celinski, V. R.; Schmedt auf der Günne, J.; Schneider, S. J. Am. Chem. Soc. 2013, 135, 13342;(f) Glüer, A.; Förster, M.; Celinski, V. R.; Schmedt auf der Günne, J.; Holthausen, M. C.; Schneider, S. ACS Catal. 2015, 5, 7214;(g) Esteruelas, M. A.; López, A. M.; Mora, M.; Oñate, E. ACS Catal. 2015, 5, 187.

(5) (a) Dallanegra, R.; Robertson, A. P. M.; Chaplin, A. B.; Manners, I.; Weller, A. S. Chem. Commun. 2011, 47, 3763;(b) Johnson, H. C.; Leitao, E. M.; Whittell, G. R.; Manners, I.; LloydJones, G. C.; Weller, A. S. J. Am. Chem. Soc. 2014, 136, 9078;(c) Johnson, H. C.; Weller, A. S. Angew. Chem. Int. Ed. 2015, 54, 10173;(d) Kumar, A.; Beattie, N. A.; Pike, S. D.; Macgregor, S. A.; Weller, A. S. Angew. Chem. Int. Ed. 2016, 55, 6651;(e) St. John, A.; Goldberg, K. I.; Heinekey, D. M. Top. Organomet. Chem. 2013, 271;(f) Kawano, Y.; Uruichi, M.; Shimoi, M.; Taki, S.; Kawaguchi, T.; Kakizawa, T.; Ogino, H. J. Am. Chem. Soc. 2009, 131, 14946;(g) Lichtenberg, C.; Adelhardt, M.; Gianetti, T. L.; Meyer, K.; de Bruin, B.; Grützmacher, H. ACS Catal. 2015, 5, 6230.

(6) Anke, F.; Han, D.; Klahn, M.; Spannenberg, A.; Beweries, T. Dalton Trans. 2017, 46, 6843.

(7) (a) Robertson, A.; Suter, R.; Chabanne, L.; Whittell, G.; Manners, I. Inorg. Chem. 2011, 50, 12680;(b) Sonnenberg, J. F.; Morris, R. H. ACS Catal. 2013, 3, 1092;(c) He, T.; Wang, J.; Wu, G.; Kim, H.; Proffen, T.; Wu, A.; Li, W.; Liu, T.; Xiong, Z.; Wu, C.; Chu, H.; Guo, J.; Autrey, T.; Zhang, T.; Chen, P. Chem. Eur. J. 2010, 16, 12814.

(8) Vance, J. R.; Schäfer, A.; Robertson, A. P. M.; Lee, K.; Turner, J.; Whittell, G. R.; Manners, I. J. Am. Chem. Soc. 2014, 136, 3048.

(9) (a) Zhang, X.; Kam, L.; Trerise, R.; Williams, T. Acc. Chem. Res. 2016, 50, 86;(b) Stubbs, N. E.; Robertson, A. P. M.; Leitao, E. M.; Manners, I. J. Organomet. Chem. 2013, 730, 84;(c) Bhattacharya, P.; Krause, J. A.; Guan, H. J. Am. Chem. Soc. 2014, 136, 1153.

(10) Alcaraz, G.; Sabo-Etienne, S. Angew. Chem. Int. Ed. 2010, 49,7170 .

(11) (a) Jaska, C. A.; Temple, K.; Lough, A. J.; Manners, I. J. Am. Chem. Soc. 2003, 125, 9424;(b) Alcaraz, G.; Vendier, L.; Clot, E.; Sabo-Etienne, S. Angew. Chem. Int. Ed. 2009, 49, 918;(c) Kumar, A.; Johnson, H. C.; Hooper, T. N.; Weller, A. S.; Algarra, A. G.; Macgregor, S. A. Chem. Sci. 2014, 5, 2546;(d) Tang, C. Y.; Phillips, N.; Bates, J. I.; Thompson, A. L.; Gutmann, M. J.; Aldridge, S. Chem. Commun. 2012, 48, 8096;(e) Phillips, N.; Tang, C. Y.; Tirfoin, R.; Kelly, M. J.; Thompson, A. L.; Gutmann, M. J.; Aldridge, S. Dalton Trans. 2014, 43, 12288;(f) Friedrich, A.; Drees, M.; Schneider, S. Chem. Eur. J. 2009, 15, 10339.

(12) (a) Johnson, H. C.; Robertson, A. P. M.; Chaplin, A. B.; Sewell, L. J.; Thompson, A. L.; Haddow, M. F.; Manners, I.; Weller, A. S. J. Am. Chem. Soc. 2011, 133, 11076;(b) Kalviri, H. A.; Gärtner, F.; Ye, E.; Korobkov, I.; Baker, R. T. Chem. Sci. 2014, 6, 618;(c) Mo, Z.; Rit, A.; Campos, J.; Kolychev, E. L.; Aldridge, S. J. Am. Chem. Soc. 2016, 138, 3306.

(13) (a) Huertos, M. A.; Weller, A. S. Chem. Sci. 2013, 4, 1881;(b) Marquardt, C.; Jurca, T.; Schwan, K.-C.; Stauber, A.; Virovets, A. V.; Whittell, G. R.; Manners, I.; Scheer, M. Angew.
Chem. Int. Ed. 2015, 54, 13782;(c) Hooper, T. N.; Weller, A. S.; Beattie, N. A.; Macgregor, S. A. Chem. Sci. 2016, 7, 2414;(d) Schäfer, A.; Jurca, T.; Turner, J.; Vance, J. R.; Lee, K.; Du, V. A.; Haddow, M. F.; Whittell, G. R.; Manners, I. Angew. Chem. Int. Ed. 2015, 54, 4836;(e) Turner, J. R.; Resendiz-Lara, D. A.; Jurca, T.; Schäfer, A.; Vance, J. R.; Beckett, L.; Whittell, G. R.; Musgrave, R. A.; Sparkes, H. A.; Manners, I. Macromol. Chem. Phys. 2017, 218 , 1700120 .

(14) Hartwig, J. F. Organotransition Metal Chemistry; University Science Books: Sausalito, USA, 2010.

(15) Metters, O. J.; Chapman, A. M.; Robertson, A. P. M.; Woodall, C. H.; Gates, P. J.; Wass, D. F.; Manners, I. Chem. Commun. 2014, 50, 12146.

(16) (a) Zimmerman, P. M.; Paul, A.; Zhang, Z.; Musgrave, C. B. Inorg. Chem. 2009, 48, 1069;(b) Bhunya, S.; Zimmerman, P. M.; Paul, A. ACS Catal. 2015, 5, 3478.

(17) (a) Robertson, A. P. M.; Leitao, E. M.; Manners, I. J. Am. Chem. Soc. 2011, 133, 19322;(b) Leitao, E. M.; Stubbs, N. E.; Robertson, A. P.; Helten, H.; Cox, R. J.; Lloyd-Jones, G. C.; Manners, I. J. Am. Chem. Soc. 2012, 134, 16805.

(18) (a) Aldridge, S.; Downs, A. J.; Tang, C. Y.; Parsons, S.; Clarke, M. C.; Johnstone, R. D. L.; Robertson, H. E.; Rankin, D. W. H.; Wann, D. A. J. Am. Chem. Soc. 2009, 131, 2231;(b) Dallanegra, R.; Chaplin, A. B.; Weller, A. S. Angew. Chem. Int. Ed. 2009, 48, 6875;(c) Chen, X.; Zhao, J.-C.; Shore, S. G. Acc. Chem. Res. 2013, 46, 2666;(d) Bellham, P.; Anker, M.; Hill, M.; Kociok-Köhn, G.; Mahon, M. Dalton Trans. 2016, 45, 13969.

(19) Chen, E. Chem. Rev. 2009, 109, 5157.

(20) Johnson, H. C.; Weller, A. S. J. Organomet. Chem. 2012 , 721-722, 17.

(21) Adams, G. M.; Weller, A. S. Coord. Chem. Rev. 2018, 355, 150 .

(22) Roselló-Merino, M.; López-Serrano, J.; Conejero, S. J. Am. Chem. Soc. 2013, 135, 10910.

(23) (a) Lu, Z.; Conley, B. L.; Williams, T. J. Organometallics 2012, 31, 6705;(b) Lunsford, A. M.; Blank, J. H.; Moncho, S.; Haas, S. C.; Muhammad, S.; Brothers, E. N.; Darensbourg, M. Y.; Bengali, A. A. Inorg. Chem. 2016, 55, 964.

(24) Bhunya, S.; Malakar, T.; Paul, A. Chem. Commun. 2014, 50,5919 .

(25) Kranenburg, M.; van der Burgt, Y. E. M.; Kamer, P. C. J.; Van Leeuwen, P. W. N. M.; Goubitz, K.; Fraanje, J. Organometallics 1995, 14, 3081 .

(26) (a) Julian, L. D.; Hartwig, J. F. J. Am. Chem. Soc. 2010, 132, 13813;(b) Haibach, M. C.; Wang, D. Y.; Emge, T. J.; KroghJespersen, K.; Goldman, A. S. Chem. Sci. 2013, 4, 3683;(c) Raebiger, J.; Miedaner, A.; Curtis, C.; Miller, S.; Anderson, O.; DuBois, D. J. Am. Chem. Soc. 2004, 126, 5502.

(27) (a) Esteruelas, M.; Oliván, M.; Vélez, A. Organometallics 2015, 34, 1911;(b) Esteruelas, M. A.; Honczek, N.; Olivan, M.; Onate, E.; Valencia, M. Organometallics 2011, 30, 2468;(c) Alós, J.; Bolano, T.; Esteruelas, M. A.; Olivan, M.; Onate, E.; Valencia, M. Inorg. Chem. 2013, 52, 6199;(d) Esteruelas, M. A.; García-Yebra, C.; Martín, J.; Oñate, E. Inorg. Chem. 2017, 56, 676;(e) Esteruelas, M. A.; López, A. M.; Oliván, M. Chem. Rev. 2016, 116, 8770.

(28) Esteruelas, M.; Nolis, P.; Oliván, M.; Oñate, E.; Vallribera, A.; Vélez, A. Inorg. Chem. 2016, 55, 7176.

(29) Shimoi, M.; Nagai, S.; Ichikawa, M.; Kawano, Y.; Katoh, K.; Uruichi, M.; Ogino, H. J. Am. Chem. Soc. 1999, 121, 11704.

(30) Pawley, R. J.; Moxham, G. L.; Dallanegra, R.; Chaplin, A. B.; Brayshaw, S. K.; Weller, A. S.; Willis, M. C. Organometallics 2010, 29, 1717.

(31) Johnson, H.; McMullin, C.; Pike, S.; Macgregor, S.; Weller, A. Angew. Chem. Int. Ed. 2013, 52, 9776.

(32) Ledger, A. E. W.; Ellul, C. E.; Mahon, M. F.; Williams, J. M. J.; Whittlesey, M. K. Chem. Eur. J. 2011, 17, 8704.

(33) Algarra, A. G.; Sewell, L. J.; Johnson, H. C.; Macgregor, S. A.; Weller, A. S. Dalton Trans. 2014, 43, 11118.

(34) Merle, N.; Koicok-Köhn, G.; Mahon, M. F.; Frost, C. G.; Ruggerio, G. D.; Weller, A. S.; Willis, M. C. Dalton Trans. 2004, 3883 . 
(35) It has been reported that complex 7 is in a slow equilbrium with an oligomeric species. ${ }^{26 \mathrm{~b}}$ We prepare 7 pure and in essentially

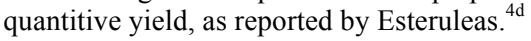

(36) Perutz, R. N.; Sabo-Etienne, S. Angew. Chem. Int. Ed. 2007, 46, 2578 .

(37) Ewing, W. C.; Marchione, A.; Himmelberger, D. W.; Carroll, P. J.; Sneddon, L. G. J. Am. Chem. Soc. 2011, 133, 17093.

(38) Ewing, W. C.; Carroll, P. J.; Sneddon, L. G. Inorg. Chem. 2013, 52, 10690 .

(39) Yang, C. J.; Jenekhe, S. A. Chem. Mat. 1994, 6, 196.

(40) This might be due to the greater difficulty of removing impurities from the longer polymer chains, or from increased $\mathrm{H}$ bonding interactions between the neutral Rh species and the polymer chains.

(41) The $\left[\mathrm{BAr}_{4}^{\mathrm{F}}\right]^{-}$contaminant has not been previously noted in related systems.[REF]

(42) Semsarilar, M.; Jones, E. R.; Armes, S. P. Polym. Chem. 2014, 5, 195.

(43) The relatively sharp peak profile for the $\left[\mathrm{BAr}_{4}^{\mathrm{F}}\right]^{-}$anion, coupled with its co-elution with polymer that tails into system peaks, results in the modelled fits giving similar $M_{\mathrm{n}}$ and $\doteq$ to raw data.

(44) Addition of 5 equivalents of $\mathrm{PPh}_{3}$ during catalysis using 6 or 11 immediately halted the production of $\mathrm{H}_{2}$. For complex 6 a $\mathrm{Rh}(\mathrm{I})-\mathrm{PPh}_{3}$ adduct is formed (see Supporting Materials). We have not characterized the products of $\mathrm{PPh}_{3}$ addition to $\mathbf{1 1}$.

(45) Ravve, A. Principles of Polymer Chemistry; 3rd Edition ed.; Springer: New York, 2012.

(46) Quirk, R.; Lee, B. Polym. Int. 1992, 27, 359.

(47) Malakar, T.; Bhunya, S.; Paul, A. Chem. Eur. J. 2015, 21, 6340 .

(48) Kim, J.; Soares, J.; Rempel, G. Macromol. Rapid Commun. 1998, 19, 197.

(49) Dorn, H.; Rodezno, J. M.; Brunnhöfer, B.; Rivard, E.; Massey, J. A.; Manners, I. Macromolecules 2003, 36, 291.

(50) (a) Colebatch, A. L.; McKay, A. I.; Beattie, N. A.; Macgregor, S. A.; Weller, A. S. Eur. J. Inorg. Chem. 2017, 4533;(b) Pike, S.; Crimmin, M.; Chaplin, A. Chem. Commun. 2017, 53, 3615.

(51) Jaska, C. A.; Manners, I. J. Am. Chem. Soc. 2004, 126, 9776.

(52) Vogt, M.; De Bruin, B.; Berke, H.; Trincado, M.; Grutzmacher, H. Chem. Sci. 2011, 2, 723.

(53) Sloan, M. E.; Staubitz, A.; Clark, T. J.; Russell, C. A.; Lloyd-Jones, G. C.; Manners, I. J. Am. Chem. Soc. 2010, 132, 3831.

(54) Sewell, L. J.; Huertos, M. A.; Dickinson, M. E.; Weller, A. S.; Lloyd-Jones, G. C. Inorg. Chem. 2013, 52, 4509.

(55) (a) Jones, W. D. Acc. Chem. Res. 2003, 36, 140;(b) Simmons, E. M.; Hartwig, J. F. Angew. Chem. Int. Ed. 2012, 51, 3066 .

(56) (a) Keaton, R. J.; Blacquiere, J. M.; Baker, R. T. J. Am. Chem. Soc. 2007, 129, 1844;(b) Todisco, S.; Luconi, L.; Giambastiani, G.; Rossin, A.; Peruzzini, M.; Golub, I.; Filippov, O.; Belkova, N.; Shubina, E. Inorg. Chem. 2017, 56, 4296.

(57) Chaplin, A. B.; Weller, A. S. Eur. J. Inorg. Chem. 2010, 5124.

(58) Braunschweig, H.; Kraft, K.; Kupfer, T.; Radacki, K.; Seeler, F. Angew. Chem. Int. Ed. 2008, 47, 4931.
(59) 3669 .

Vidovic, D.; Aldridge, S. Angew. Chem. Int. Ed. 2009, 48,

(60) Alcaraz, G.; Helmstedt, U.; Clot, E.; Vendier, L.; SaboEtienne, S. J. Am. Chem. Soc. 2008, 130, 12878.

(61) O'Neill, M.; A Addy, D.; Riddlestone, I.; Kelly, M.; Phillips, N.; Aldridge, S. J. Am. Chem. Soc. 2011, 133, 11500.

(62) DFT calculations on a Xantphos-H model system also retained this geometry suggesting that electronic effects are also relevant

(63) Braunschweig, H.; Dewhurst, R. D.; Gessner, V. H. Chem Soc. Rev. 2013, 42, 3197.

(64) Douglas, T.; Chaplin, A.; Weller, A.; Yang, X.; Hall, M. J. Am. Chem. Soc. 2009, 131, 15440.

(65) Borrachero, M. V.; Estevan, F.; Garcia-Granda, S.; Lahuerta, P.; Latorre, J.; Peris, E.; Sanau, M. J. Chem. Soc., Dalton Trans. 1993, 1864.

(66) Species 14 was fully optimised using the BP86 functional. $\mathrm{Rh}$ and $\mathrm{P}$ centers were described with SDD RECPs and associated basis sets while 6-31g** basis sets were used for all other atoms. See Supporting Materials for full details and references.

(67) We cannot rule out the identity of $\mathbf{1 5}$ as the linear diborazane complex [Rh $\left(\kappa^{3}-\mathrm{P}, \mathrm{O}, \mathrm{P}-\mathrm{X}\right.$ antphos$\left.\left.{ }^{\mathrm{i}} \mathrm{Pr}\right)(\mathrm{H})_{2}\left(\mathrm{H}_{3} \mathrm{~B} \cdot \mathrm{NMeHBH}_{2} \cdot \mathrm{NMeH}_{2}\right)\right]\left[\mathrm{BAr}_{4}^{\mathrm{F}}\right]$, as independent synthesis showed NMR data very similar to complex $\mathbf{1 5}$

(68) Kumar, R.; Jagirdar, B. Inorg. Chem. 2013, 52, 28

(69) (a) Denney, M. C.; Pons, V.; Hebden, T. J.; Heinekey, D. M.; Goldberg, K. I. J. Am. Chem. Soc. 2006, 128, 12048;(b) Lin, T.P.; Peters, J. C. J. Am. Chem. Soc. 2013, 135, 15310.

(70) Robertson, A. P. M.; Haddow, M. F.; Manners, I. Inorg Chem. 2012, 51, 8254 .

(71) (a) Fehlner, T. P. Organometallics 2000, 19, 2643;(b) Maekawa, M.; Daniliuc, C. G.; Jones, P. G.; Hohenberger, J.; Sutter, J.; Meyer, K.; Walter, M. D. Eur. J. Inorg. Chem. 2013, 4097.

(72) Kumar, A.; Ishibashi, J.; Hooper, T.; Mikulas, T.; Dixon, D.; Liu, S.; Weller, A. Chem. Eur. J. 2016, 22, 310.

(73) Goldberg, J. M.; Wong, G. W.; Brastow, K. E.; Kaminsky, W.; Goldberg, K. I.; Heinekey, D. M. Organometallics 2015, 34, 753.

(74) Calculations demonstrate that Xantphos- ${ }^{\mathrm{t}} \mathrm{Bu}$ III is unstable with respect to $\mathrm{H}_{2}$ loss and formation of 13 [ref. 26b]. Given that speciation is demonstrated to be markedly different for cationic $\mathbf{6}$ and neutral 13 precatalysts we suggest this is kinetically not relevant, and $\mathrm{H}_{2}$ loss is relatively slow in the ${ }^{\mathrm{i}} \mathrm{Pr}$ system.

(75) Roselló-Merino, M.; Rama, R.; Díez, J.; Conejero, S. Chem. Commun. 2016, 52, 8389.

(76) Interestingly, the addition of $\left[\mathrm{BH}_{2}\left(\mathrm{NMeH}_{2}\right)_{2}\right]^{+}$also led to an increase in the induction period by $\sim 10$ minutes.

(77) (a) Addy, D. A.; Bates, J. I.; Kelly, M. J.; Riddlestone, I. M.; Aldridge, S. Organometallics 2013, 32, 1583;(b) Drover, M.; Bowes, E.; Schafer, L.; Love, J.; Weller, A. Chem. Eur. J. 2016, 22, 6793.

(78) Stephens, F. H.; Baker, R. T.; Matus, M. H.; Grant, D. J.; Dixon, D. A. Angew. Chem. Int. Ed. 2007, 46, 746.

(79) Choi, J.; MacArthur, A. H. R.; Brookhart, M.; Goldman, A. S. Chem. Rev. 2011, 111, 1761 .

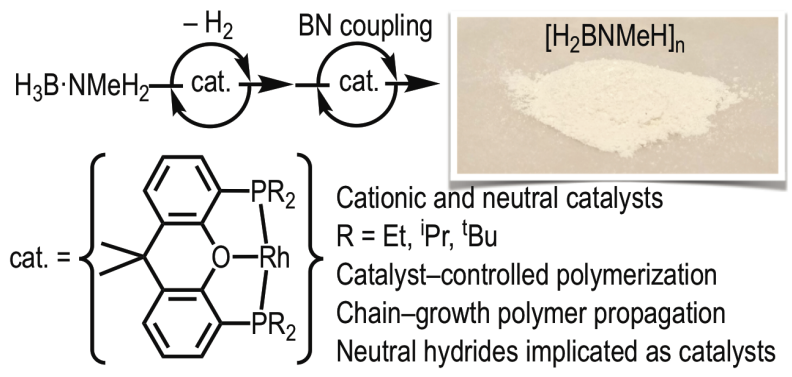

For ToC 